\title{
Review \\ Recent Advances in Theoretical Development of Thermal Atomic Layer Deposition: A Review
}

\author{
Mina Shahmohammadi ${ }^{1}$, Rajib Mukherjee ${ }^{2,3}$, Cortino Sukotjo ${ }^{4}$ (), Urmila M. Diwekar ${ }^{2,5, *(1)}$ \\ and Christos G. Takoudis ${ }^{1,5, *}$ \\ 1 Department of Chemical Engineering, University of Illinois at Chicago, Chicago, IL 60607, USA; \\ mshahm2@uic.edu \\ 2 Vishwamitra Research Institute, Crystal Lake, IL 60012, USA; rmukhe0@gmail.com \\ 3 Department of Chemical Engineering, University of Texas Permian Basin, Odessa, TX 79762, USA \\ 4 Department of Restorative Dentistry, University of Illinois at Chicago, Chicago, IL 60612, USA; \\ csukotjo@uic.edu \\ 5 Department of Biomedical Engineering, University of Illinois at Chicago, Chicago, IL 60607, USA \\ * Correspondence: urmila@vri-custom.org (U.M.D.); takoudis@uic.edu (C.G.T.)
}

\section{check for}

updates

Citation: Shahmohammadi, M.;

Mukherjee, R.; Sukotjo, C.; Diwekar,

U.M.; Takoudis, C.G. Recent

Advances in Theoretical

Development of Thermal Atomic

Layer Deposition: A Review.

Nanomaterials 2022, 12, 831.

https://doi.org/10.3390/

nano12050831

Academic Editor: Sotirios

Baskoutas

Received: 12 February 2022

Accepted: 25 February 2022

Published: 1 March 2022

Publisher's Note: MDPI stays neutral with regard to jurisdictional claims in published maps and institutional affiliations.

Copyright: (C) 2022 by the authors. Licensee MDPI, Basel, Switzerland. This article is an open access article distributed under the terms and conditions of the Creative Commons Attribution (CC BY) license (https:// creativecommons.org/licenses/by/ $4.0 /)$.

\begin{abstract}
Atomic layer deposition (ALD) is a vapor-phase deposition technique that has attracted increasing attention from both experimentalists and theoreticians in the last few decades. ALD is well-known to produce conformal, uniform, and pinhole-free thin films across the surface of substrates. Due to these advantages, ALD has found many engineering and biomedical applications. However, drawbacks of ALD should be considered. For example, the reaction mechanisms cannot be thoroughly understood through experiments. Moreover, ALD conditions such as materials, pulse and purge durations, and temperature should be optimized for every experiment. It is practically impossible to perform many experiments to find materials and deposition conditions that achieve a thin film with desired applications. Additionally, only existing materials can be tested experimentally, which are often expensive and hazardous, and their use should be minimized. To overcome ALD limitations, theoretical methods are beneficial and essential complements to experimental data. Recently, theoretical approaches have been reported to model, predict, and optimize different ALD aspects, such as materials, mechanisms, and deposition characteristics. Those methods can be validated using a different theoretical approach or a few knowledge-based experiments. This review focuses on recent computational advances in thermal ALD and discusses how theoretical methods can make experiments more efficient.
\end{abstract}

Keywords: atomic layer deposition (ALD); precursors; mechanisms; deposition characteristics density functional theory; molecular dynamics; lattice Boltzmann method; Monte Carlo; group contribution method; computer-aided molecular design

\section{Introduction}

Atomic layer deposition (ALD) is a vapor-phase technique to deposit thin-film materials on various substrates through sequential and self-limiting surface reactions [1]. ALD originated from two different methods: atomic layer epitaxy (ALE) and molecular layering (ML), which were first introduced in the 1970s [2]. ALD then emerged due to the need for precise film thickness on small devices with high aspect ratios [2-4]. The thin films produced by ALD are deposited using chemical gas or vapor phase species, called precursors, in a cyclic fashion [5]. Thus, ALD is often called an advanced form of chemical vapor deposition (CVD). However, unlike CVD, ALD consists of alternative pulses and purges of the precursors, resulting in deposition of the desired film with an expected thickness and composition $[5,6]$. Furthermore, ALD is often performed under vacuum and at various ranges of temperatures, from room temperatures up to high temperatures, due to which ALD has a wide temperature window [4]. 
Each cycle is composed of two half-cycles or half-reactions, in which up to one monolayer of a metal or metal oxide is deposited on the surface of the substrate [3]. During the first half-cycle, the precursor is carried by inert gas and pulsed into the reactor with a determined duration, reacts with the available active sites of the substrate, and is chemisorbed on the surface [5]. In this step, ideally, the precursor saturates the surface through a self-limiting reaction. Then, excess unreacted precursor molecules are purged out of the chamber using inert gas. In the second half-cycle, the co-reactant pulses into the reactor to react with the adsorbed precursor molecules on the substrate $[7,8]$. The common coreactants for ALD are water vapor, $\mathrm{O}_{2}, \mathrm{O}_{3}$, and $\mathrm{NH}_{3}$ [9]. Finally, the excess co-reactant molecules and the by-products of the reaction are purged out of the reactor. These two half-cycles are repeated until the required film thickness and composition are achieved [10]. The schematic of an ALD cycle is presented in Figure 1.
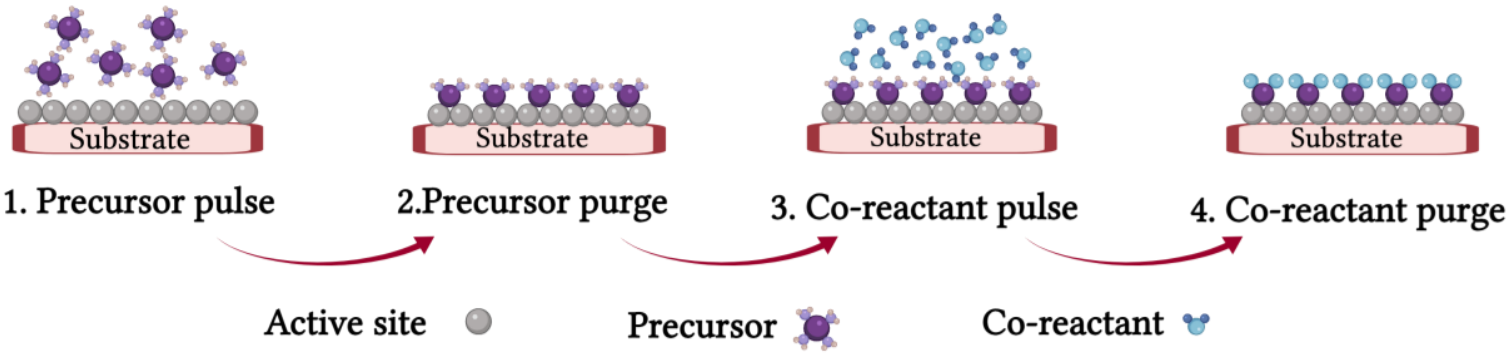

Active site

Precursor

Co-reactant $ช$

Figure 1. Schematic of each ALD cycle (Created with BioRender.com).

The thin film deposition technique of ALD has a wide range of applications $[3,5,9,10]$. Some of the important applications of ALD include but are not limited to the following areas: semiconductor engineering [11-13], lithium-ion batteries [14-16], microelectromechanical systems (MEMS) [17,18], capacitors [19,20], fuel cells [21-23], solar cells [24-26], transistors [27-29], drug delivery [30,31], medical and biomedical fields [32-35], dental materials [6,10], and orthopedical implants [36-38]. Due to the capability of precisely depositing conformal ultra-thin films, ALD has found a wide range of applications in the fabrication of microelectronics such as gate oxides, semiconductors, and ferroelectrics [12,39,40]. This technique has also attracted much attention in medical and biomedical applications, where organic substrates such as polymers or biomaterials are required [6,34,41].

Previous works have reviewed the important advantages and disadvantages of ALD $[5,10,42,43]$. The films produced by ALD are ultra-thin with exact controllability over thickness, composition, and crystallinity at the Ångström level [4]. The films are also uniform, conformal, and pinhole-free across various substrates, even those with high aspect ratios or complex three-dimensional (3D) structures [43,44]. Additionally, many different metals, oxides, nitrides, sulfides, selenides, tellurides, fluorides, and metal-organic frameworks (MOFs) can be deposited by ALD as long as the associated precursors exist $[3,9,10,42,45]$. A wide range of temperatures can be used in ALD depending on different properties such as the nature of the materials involved and the final applications. ALD can produce high-quality films even at low substrate temperatures [46].

Being a slow process is one of the main drawbacks of ALD [3]. Depending on the conditions, a 100-nm thin film with thermal ALD would take around $20 \mathrm{~h}$ or more to deposit. Although spatial ALD (SALD) has been developed to overcome this drawback [47], it is a rather new tool and not always accessible. Moreover, SALD can be sensitive to ambient air if performed in open air, highly volatile precursors are needed for SALD, and, still, not many precursors for SALD exist [47]. Before each ALD experiment, all the conditions should be determined to find the optimized ones. Thus, for each ALD experiment, different questions need to be answered:

- What would be the final applications?

- What materials (i.e., precursor, oxidizer, and substrate) should be used?

- How long should the pulse and purge durations be to obtain a high-quality film?

- What would be the growth rate based on the determined conditions? 
- What should be the temperature and pressure of the reactor and the precursor bubblers?

- Are all the materials stable in those conditions?

Deciding on each of these factors requires many experiments to adjust the conditions resulting in high-quality films and an optimized growth rate. Moreover, each experiment should be repeated a few times to validate the results and ensure the reproducibility of the samples. On the other hand, the common precursors for ALD are often expensive, and performing many experiments to tune the conditions is inefficient. Additionally, some of the mechanisms result in hazardous by-products, and it is preferred to reduce the number of experiments. Theoretical modeling is one of the ways to find optimal conditions without performing any experiments, which would tremendously reduce the cost and time associated with those experiments.

Recently, many research studies have used computer simulations and theoretical models in conjunction with ALD for a variety of purposes, such as the study of thin film structure and composition and material selection [48]. The modeling technique varies over multiple scales and is based on the interaction between atoms, molecules, particles, and groups of atoms, also known as functional groups. Here, we present an overview of the common theoretical methods used to model ALD and the insight that can be obtained about the process of ALD from the different types of modeling. Thus, we adopt a reverse engineering approach, where we define various aspects of ALD, describe the experimental procedure used for ALD process development, and describe how modeling and simulation have been used for a proper understanding and improvement of the ALD process. The rest of the paper is organized as follows. First, different aspects of ALD are briefly introduced and discussed, then the computational methods commonly used for modeling and simulation of ALD are presented, and, finally, recent studies on theoretical approaches to ALD are reviewed.

\section{Aspects of ALD}

Extensive experimental and theoretical research has so far been performed on different aspects of ALD. Experimentalists often focused on one or some of the following areas: precursors, mechanisms happening in an ALD reactor, and deposition characteristics such as temperature window, saturating pulse and purge times, growth rate, composition, morphology, and surface properties of the deposited film. Since conventional ALD is a slow process and due to the disadvantages of SALD mentioned above, many time-consuming and expensive experiments are required to tune an ALD condition for desired applications. Thus, not many of the areas mentioned above would be examined in a single research study, and the researchers usually focus on a few of them when studying ALD systems.

\subsection{ALD Precursors}

An ALD precursor is often a metal surrounded by organic functional groups held in a vessel known as a bubbler. The bubbler temperature in an ALD system varies depending on the properties of the precursor. ALD precursors are volatile, thermally stable, and highly reactive [49]. A few physical properties are considered when selecting a precursor for an ALD study, such as materials of interest, reactivity toward the other co-reactant, ALD conditions, final applications, and desired film properties (e.g., dielectric constant, adsorption capacity, gas impermeability, leakage current, electrical conductivity, photochemical activity, and antimicrobial activity) [49-53].

Precursors should be able to react quickly with the active sites of the substrates and other precursor molecules. Hence, precursor chemistry is a key factor in an ALD process, which also affects the growth mechanisms. In recent years, the introduction of new precursors has attracted much attention. Theoretical methods are appropriate for designing new materials based on existing experimental data and predicting their properties before synthesizing them [6]. Moreover, first-principles calculations can be used to suggest new materials with predicted properties that would be proved later through experiments $[39,54,55]$. In addition, there is often the need to compare ALD precursors in 
terms of various aspects that could become practically impossible through experimentation. Theoretical approaches are useful for these purposes.

\subsection{Deposition Characteristics}

\subsubsection{Growth}

The growth rate in ALD is defined as the thickness of the film divided by the number of cycles (nm/cycle) and depends on multiple factors, including the precursor flux reaching the substrate [5]. The growth rate is a prime factor in ALD studies since it provides a direct method to understand the amount of time each deposition takes and predict the film thickness before deposition. Thus, the growth rate is often reported for each system under study. In addition, the growth rate is affected by the reactor temperature and pressure, pulse and purge times of the reactants, and the nature of the substrate. The growth rate is often reported as a constant value (the slope of the plot showing film thickness versus the number of cycles); however, some studies reported that the growth rate might change over the number of cycles. For instance, a recent study reported duo-linear plots of $\mathrm{TiO}_{2}$ film thickness versus the number of ALD cycles. According to them, absorbed water molecules in pores of a polymethyl methacrylate (PMMA) substrate were released into the reactor during the initial cycles, affecting the growth mechanism and resulting in a higher growth rate compared with later deposition cycles (Figure 2) [6].

$\mathrm{TiO}_{2}$ ALD on PMMA and silicon reference substrates

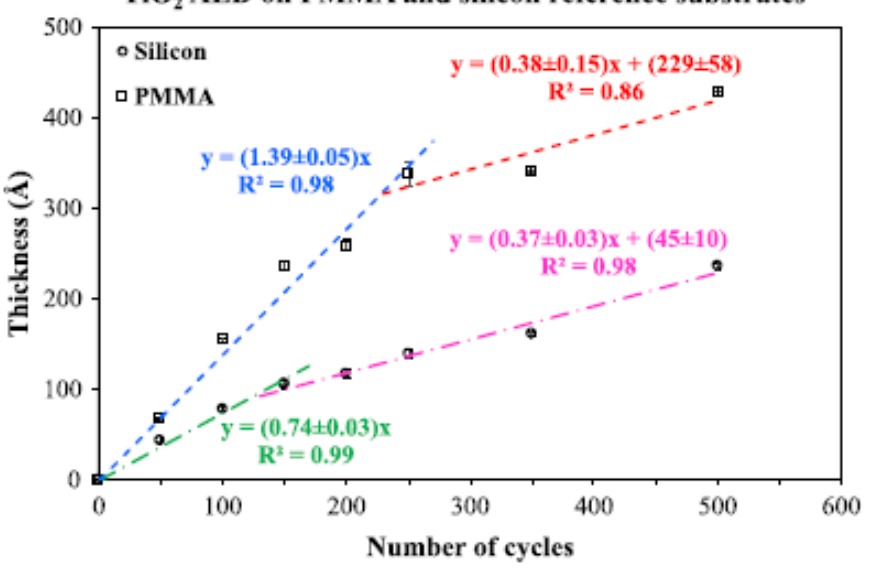

Figure 2. Duo-linear plot of $\mathrm{TiO}_{2}$ film thickness versus the number of cycles and a silicon reference (reprinted with permission from [6]).

Another aspect of ALD growth is the growth mode, meaning how the materials are arranged on the surface of the substrate during ALD growth [56]. The ALD growth modes are mainly attributed to one of the following modes: Volmer-Weber growth, Frank-van der Merwe growth, and Stranski-Krastanov growth [57,58]. In the Volmer-Weber growth mode, also known as island growth, small clusters or islands are first nucleated on the surface. The reason for island nucleation, in this case, is that the interaction of the adsorbed atoms within themselves is stronger compared with the interaction between the atoms and the substrate. That is, the cohesive force within the atoms is stronger than the surface adhesive force, so the atoms tend to accumulate. Then, those small clusters grow into larger three-dimensional ones and reach each other, covering the whole surface [57].

On the other hand, in the Frank-van der Merwe growth mode, also known as bidimensional growth, the surface adhesive force is stronger than the intra atom cohesive force, leading to layer-by-layer growth on the substrate. That is, the atoms completely cover the surface, producing a complete monolayer before the subsequent layer is formed on top [59]. If both the Volmer-Weber and Frank-van der Merwe growth modes are combined, the growth mode is called Stranski-Krastanov. In the Stranski-Krastanov growth mode, which is the more common growth mode, the film starts to form on the surface of the substrate as a whole layer. After forming a rather thick film, the growth mode switches to 
island growth [58]. Where the transition happens is affected by the chemical and physical properties of both film and substrate materials [57-59]. Figure 3 presents a schematic of the three growth modes.

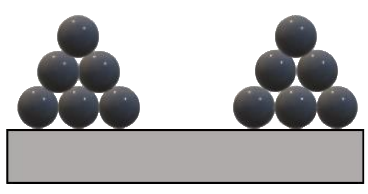

(a) Volmer-Weber

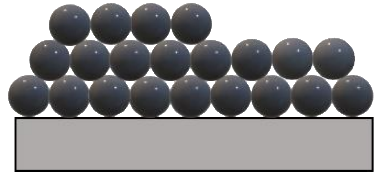

(b) Frank-van der Merwe

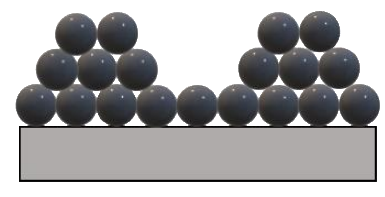

(c) Stranski-Krastanov

Figure 3. Schematic of common growth modes in ALD: (a) Volmer-Weber; (b) Frank-van der Merwe; and (c) Stranski-Krastanov.

\subsubsection{Surface Morphology}

Surface morphology is another characteristic of thin films usually examined and reported in ALD-related studies. Different techniques, such as atomic force microscopy (AFM), profilometry, and scanning electron microscopy (SEM), are used to scan the surface and provide three-dimensional images of surface topography. Surface morphology depends on many factors, including nucleation and growth mechanisms, growth rate, crystallinity, surface roughness, deposition conditions, substrate, and impurities [60,61].

\subsubsection{Surface Roughness}

Another thin-film property that is often investigated in ALD studies is surface roughness. Roughness is a part of surface texture, defined as a measure of waviness or irregularities on the film surface. Mapping technologies such as AFM and optical or contact profilometry can be used to calculate the surface roughness. The surface roughness is significantly affected by the growth mode discussed earlier. For instance, the Volmer-Weber growth mode starts with island nucleation; the islands enlarge over time, and, most likely, their heights become larger than the thickness of one monolayer before they converge. Thus, if the growth follows the Volmer-Weber growth mode, the film is often made of rough layers. However, due to the layer-by-layer nature of the Frank-van der Merwe growth mode, smoother films are produced with this growth mode [57]. Aside from the growth modes, the surface roughness depends on other factors such as crystallinity, film thickness, and the nature of the substrate.

\subsubsection{Step Coverage (Conformality)}

Conformality can be defined as the deposition of a film with the same thickness on all topographic features, including the top, sides, and bottom surfaces of a three-dimensional substrate [62]. Since deposition in ALD happens through surface-controlled reactions, the thin films formed have excellent conformality. That is, the step coverage provided by ALD to the surface of complex structures is higher than that of conventional deposition processes such as CVD and physical vapor deposition (PVD). Conformality is a significant aspect, especially when there is a great desire to coat a complex three-dimensional nanostructured surface or substrates with high aspect ratios [63]. Recently, Cremers et al. [63] provided an extensive review of different aspects of our current knowledge about conformality in ALD processes.

\subsubsection{Deposition Temperature}

In thermal ALD, the temperature is the main driving force for the process. One of the terms in ALD studies is the temperature window, defined as the temperature range over which the self-controlled growth would occur at a constant rate. Inside the ALD window, the growth rate would change significantly with an increase in the temperature due to the physisorption/condensation of precursors on the surface or low reaction rates, leading to uncontrolled growth. At temperatures outside the ALD window, the precursor molecules may decompose or desorb the heated substrate, resulting in uncontrolled growth [64]. The 
typical temperature window for thermal ALD processes is $150-350{ }^{\circ} \mathrm{C}$ [5], although some studies reported a temperature window out of this range. For instance, for the organic and heat-sensitive substrates, the reactor temperature should be adjusted accordingly to prevent the deformation and degradation of the substrate. Room temperature ALD has been reported on collagen materials for biomaterial functionalization [34,65].

\subsection{Thermal ALD Mechanisms}

\subsubsection{Mechanisms}

As previously mentioned, a binary ALD process consists of a dose-purge-dose-purge sequence of each reactant forming an ALD cycle. In thermal ALD, the surface reactions typically happen due to a relatively high temperature. The self-limiting nature of ALD allows for saturation to occur on the surface of the substrate during the dosage steps before the extra unreacted materials are purged out of the reactor. That is, after the chemisorbed species saturate all the available active sites, no more chemisorption would happen beyond that point, although more reactants exist in the reactor [66]. However, the exact mechanisms of ALD reactions remain sophisticated and challenging subjects. Nevertheless, some studies have modeled and predicted ALD reaction mechanisms. The ALD mechanisms are divided into three categories (initial surface reactions, reaction pathways, and precursor decomposition), each of which is briefly discussed below.

\subsubsection{Initial Surface Reactions}

A finite number of active sites are available on the surface of a substrate per each ALD cycle. Through the initial surface reactions in an ALD process, those active sites are occupied by the reactants and depleted at the end of each half-cycle, and then more active sites are created in a subsequent halfcycle. The initial growth per cycle in ALD depends on the number of nucleation sites and is categorized into three groups: linear, surface-enhanced, and surface-inhibited [67].

\subsubsection{Reaction Pathways}

When describing the reaction pathways occurring in an ALD reactor, the formation of aluminum oxide $\left(\mathrm{Al}_{2} \mathrm{O}_{3}\right)$ from trimethylaluminum (TMA) and water $\left(\mathrm{H}_{2} \mathrm{O}\right)$ is welldiscussed. TMA acts as the aluminum precursor in that system, and water is the oxygen source. The simplified forms of some of the common and well-known reaction pathways in ALD processes are summarized and tabulated here (Table 1).

Table 1. Well-known ALD reaction pathways.

\begin{tabular}{|c|c|c|c|c|}
\hline $\begin{array}{l}\text { Thin } \\
\text { Film }\end{array}$ & Precursor & Co-Reactant & Reaction Pathway & Refs. \\
\hline $\mathrm{Al}_{2} \mathrm{O}_{3}$ & $\mathrm{TMA}^{\mathrm{a}}$ & $\mathrm{H}_{2} \mathrm{O}$ & $\begin{array}{c}-\mathrm{OH}+\mathrm{AlMe}_{3} \rightarrow-\mathrm{OAlMe}+(3-\mathrm{n}) \mathrm{CH}_{4} \\
-\mathrm{AlMe}+\mathrm{H}_{2} \mathrm{O} \rightarrow-\mathrm{AlOH}+\mathrm{CH}_{4}\end{array}$ & [62] \\
\hline $\mathrm{MO}_{2} \mathrm{~b}$ & $\mathrm{MCl}_{4}$ & $\mathrm{H}_{2} \mathrm{O}$ & $\begin{array}{c}\mathrm{n}(-\mathrm{OH})+\mathrm{MCl}_{4} \rightarrow(-\mathrm{O}-)_{\mathrm{n}} \mathrm{MCl}_{4-\mathrm{n}}+\mathrm{n} \mathrm{HCl} \\
(-\mathrm{O}-)_{\mathrm{n}} \mathrm{MCl}_{4-\mathrm{n}}+(4-\mathrm{n}) \mathrm{H}_{2} \mathrm{O} \rightarrow \\
(-\mathrm{O}-)_{\mathrm{n}} \mathrm{M}(\mathrm{OH})_{4-\mathrm{n}}+(4-\mathrm{n}) \mathrm{HCl}\end{array}$ & {$[68-70]$} \\
\hline $\mathrm{MO}_{2}$ & TDMAM $^{\mathrm{c}}$ & $\mathrm{H}_{2} \mathrm{O}$ & $\begin{aligned} \mathrm{M}\left(\mathrm{NMe}_{2}\right)_{4} & +2 \mathrm{H}_{2} \mathrm{O} \rightarrow \mathrm{MO}_{2} \text { (solid) } \\
& +4 \mathrm{HNMe}_{2}\end{aligned}$ & [71] \\
\hline
\end{tabular}

a TMA, trimethylaluminum; ${ }^{\mathrm{b}} \mathrm{M}=\mathrm{Ti}, \mathrm{Hf}, \mathrm{Zr} ;{ }^{\mathrm{c}} \mathrm{TDMAM}$, tetrakis(dimethylamido)metal (Ti, Hf, or $\mathrm{Zr}$ ).

\subsubsection{Precursor Chemisorption}

Previous studies are focused on describing different mechanisms of precursor chemisorption during an ALD process. These mechanisms are mainly categorized into three groups (ligand exchange, dissociation, and association) [66,72]. In ligand exchange chemisorption, the split of the precursor occurs on the surface, where its ligand is exchanged with a surface group, and a gaseous product is released [66]. In the dissociation process, one or 
more ligands of the precursors are separated from the molecule, bounded with the surface groups, and create active sites on the substrate [66]. The molecule fragments are usually separated due to an external source such as light or heat [72]. On the other hand, in the association process, no ligand is split from the precursor, and a coordinated bond is formed between the precursor and the surface active sites [66]. A schematic of these mechanisms was reprinted from reference [73] and is shown in Figure 4.

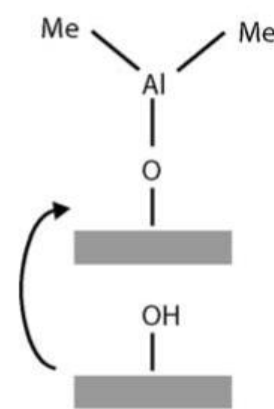

(a)

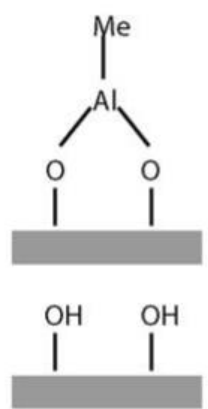

(b)

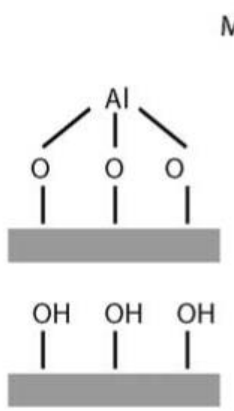

(c)

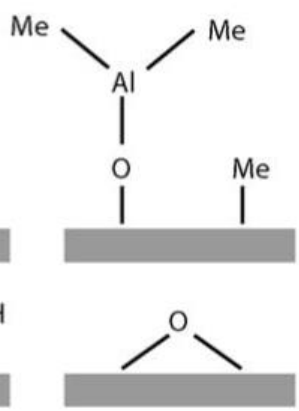

(d)

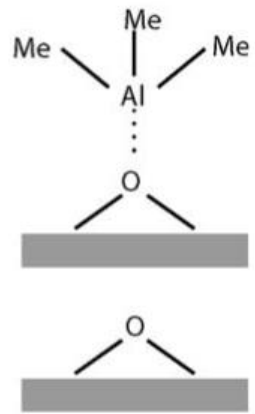

(e)

Figure 4. Schematic illustration of the TMA reaction possibilities on oxide surfaces: ligand exchange with (a) one, (b) two, and (c) three $\mathrm{OH}$ groups; (d) dissociation; and (e) association (reprinted with permission from [73]).

An example of ligand exchange precursor chemisorption is the $\mathrm{Al}_{2} \mathrm{O}_{3}$ ALD from TMA and $\mathrm{H}_{2} \mathrm{O}$, the pathway of which is shown in Figure 4. During the first half-cycle of the reaction, TMA molecules chemisorb on a hydroxylated surface and react with the $\mathrm{OH}$ groups, where a ligand exchange occurs, and methane gas is released. After the surface is thoroughly saturated with the TMA molecules, all unreacted precursors and the byproducts of the reactions are purged out. Water molecules enter the reactor in the second half-reaction and react with the $\mathrm{CH}_{3}$-terminated surface sites. Again, the ligand exchange happens between the $\mathrm{CH}_{3}$ groups of chemisorbed TMA molecules, and $\mathrm{OH}$ groups of water vapor and methane gas are released until all the active sites are filled. Lastly, by-products and unreacted water molecules are pumped out of the reactor [62]. The surface is now hydroxylated again, and the steps are repeated. Another example of ligand-exchange ALD reactions is the deposition of metal oxides using alkoxide precursors [74]. ALD of metals such as copper, ruthenium, and platinum often occurs based on dissociation chemisorption $[72,75]$. The association mechanism is the hardest to identify since it usually happens after a gas-phase dissociation or before a ligand-exchange reaction. A common example is ALD from metal halide precursors [72].

\section{Theoretical Methods}

\subsection{Density Functional Theory}

Density Functional Theory (DFT) is one of the computational methods based on the interaction between particles. DFT is used to investigate the electronic structure of manybody systems by reducing a 3N-dimensional problem to N 3-dimensional problems. In DFT, the structure of molecules may be predicted via the calculation of total energies and forces [75]. There are several examples where DFT has been broadly used along with ALD. DFT can be used to perform precursor design and comparison, predict ALD deposition characteristics such as overall growth, predict activation barriers and transition states, and determine reaction mechanisms such as initial surface reactions, reaction pathways, and the precursor chemisorption process [48,76-80].

\subsection{Microscopic or Atomic Modeling Scale: Molecular Dynamics}

Molecular Dynamics (MD) can be used to simulate the interaction between particles [81]. In MD simulations, Newton's equation of motion is integrated and numerically solved for simulating the movement of atoms and molecules $[5,82]$. MD simulation is capa- 
ble of studying rather large systems for a relatively long time and results in the trajectory of the particles as a function of time [81]. For instance, when it comes to predicting the reaction pathways or precursor chemisorption processes in ALD, MD simulation is another method that is extremely helpful $[75,83]$.

\subsection{Lattice Boltzmann Method}

The Lattice Boltzmann Method (LBM) is one of the methods used in Computational Fluid Dynamics (CFD), which was introduced in the late 1980s and is used for fluid simulations [84,85]. LBM is categorized as being on the mesoscopic modeling scale, which is appropriate for less complex systems as it needs less memory and has a short processing time [86]. This method employs the Boltzmann equation to model a fluid consisting of fictitious particles that are propagating and colliding [87]. LBM can be used along with ALD to simulate the flow of gases [86].

\subsection{Off-Lattice Pseudo-Particle Method: Monte Carlo}

Monte Carlo simulation is a stochastic computational technique to predict the probability of outcomes of various processes and obtain numerical results [88]. Monte Carlo can be used to solve intractable analytical problems or substitute for time-consuming or expensive experiments. Furthermore, researchers can employ this simulation technique to explore different aspects or modify the conditions of an experiment [88]. Random-based has a broad range of applications in finance, engineering, and science [89-92]. Monte Carlo simulation has been extensively used along with ALD for different purposes, e.g., determining film and precursor properties and the evolution of film morphology, modeling film growth, and studying the kinetics of reactions and the mechanism of materials processing in ALD [93-97]. Moreover, Kinetic Monte Carlo (kMC) simulation, which accounts for changes in the process with time, is invaluable in bridging the gap between individual reaction data from DFT and average growth characteristics from experiments [97].

\subsection{Group Contribution Method}

The Group Contribution Method (GCM) can be employed to estimate the binary interaction parameters between different groups of atoms [98] where there is no available experimental data and can avoid the need for expensive experiments. In the GCM, the thermodynamic properties of a compound are predicted from its molecular structure. For this purpose, the molecule is split up into structural and functional groups composed of individual atoms or small groups of atoms. The GCM parameter of a functional group is estimated by the number of times a particular group appears on the adsorbent, multiplied by its contribution [99]. The GCM can be employed to estimate the thermodynamic properties of precursors used in ALD. For instance, ALD precursor molecules can be divided into smaller groups of atoms, and the GCM estimates the binary interaction parameters between those groups. Then, the activity coefficients of each group can be calculated based on those interaction parameters. Our group recently reported the thermodynamic properties of some well-known precursor molecules, which will be discussed in detail later [100,101].

\subsection{Computer-Aided Molecular Design}

Computer-Aided Molecular Design (CAMD) generates molecules with desired properties from functional groups using a reverse technique to that of the GCM. While the GCM estimates the molecular properties based on the functional groups comprising the molecule, CAMD, on the other hand, combines different functional groups to generate molecules having desired properties [102]. CAMD methods have been applied extensively in various areas such as extraction solvents [103-108], polymer designs [109,110], degreasing solvents [111], blanket wash solvents [112,113], absorption solvents [114-118], refrigerant design [119,120], distillation solvents [102,106,121,122], reaction solvents [123,124], catalysts [124], value-added products [125], crystallization solvents [126], and foaming agents [127]. CAMD has been used effectively to design novel clay-based adsorbents to 
adsorb radioactive elements from flowback/produced water [128] and remove arsenic from water [129]. Mukherjee et al. [110] used CAMD to design a novel polymer resin for metal ion removal from water. CAMD is also an appropriate method to be combined with ALD, especially to design novel precursor materials, which will be discussed later on [100].

\section{Theoretical Studies on ALD}

In the previous sections, different aspects of ALD as well as theoretical methods to study the ALD technique were briefly discussed. In this section, the previous research studies on theoretical ALD are reviewed. Table 2 summarizes the theoretical-study-only ALD articles found in the Web of Science and covered in this review. It is worth mentioning that this review mostly focuses on the theoretical-study-only ALD articles and does not cover the combined experimental and theoretical ones, which are cited here [75,76,130-156]. Figure 5 displays the publications, summarized in Table 2, that are covered in this study. Figure 5a illustrates the time evolution of publications on ALD studied with at least one of the theoretical methods mentioned above. In this figure, the theoretical-study-only articles are separated from the total set of articles, i.e., those that combine theory and experiments. During the last six years, researchers have focused more on combining experimental ALD studies with theory rather than performing a purely theoretical study. The reason most likely lies within the greater desire to validate experimental data with a computational model to establish their ALD method better. Figure $5 b$ categorizes the publications based on the regions those studies were performed in.

Table 2. Summary of the theoretical-study-only ALD articles.

\begin{tabular}{|c|c|c|c|}
\hline Materials & Aspect of Study & Theoretical Method & References \\
\hline $\mathrm{Al}_{2} \mathrm{O}_{3}$ & $\begin{array}{c}\text { Introduce new precursor } \\
\text { Predict decomposition mechanism, chemisorption } \\
\text { process, growth rate, intermediates of the reaction and } \\
\text { their concentration, oxidizer reactivity, film thickness, } \\
\text { and sticking coefficients } \\
\text { Correlate growth rate quantitatively with hydroxyl } \\
\text { group concentrations } \\
\text { Simulate film uniformity, roughness, density, atomic } \\
\text { ratio, gas flow, temperature profile, and } \\
\text { surface reactions }\end{array}$ & $\begin{array}{l}\text { DFT; Mass balance; Monte } \\
\text { Carlo; CFD; } \\
\text { Numerical model/ANSYS } \\
\text { Fluent; MD }\end{array}$ & {$[73,78,83,93,96,157-165]$} \\
\hline $\mathrm{HfO}_{2}$ & $\begin{array}{c}\text { Compare two precursors } \\
\text { Predict growth rate and mechanisms } \\
\text { Design novel precursors } \\
\text { Simulate gas flow and temperature profile }\end{array}$ & $\begin{array}{l}\text { DFT; GCM/CAMD; CFD; } \\
\text { Monte Carlo }\end{array}$ & $\begin{array}{c}{[70,74,79,100,162,166-} \\
168]\end{array}$ \\
\hline $\mathrm{TiO}_{2}$ & $\begin{array}{l}\text { Compare halide precursors } \\
\text { Kinetics of reactions } \\
\text { Design novel precursors } \\
\text { Predict growth rate and mechanisms }\end{array}$ & DFT; GCM/CAMD & {$[77,100,101,161,169,170]$} \\
\hline $\mathrm{ZrO}_{2}$ & Predict mechanisms and growth & DFT & {$[80,170-173]$} \\
\hline $\mathrm{ZnO}$ & $\begin{array}{l}\text { Simulate growth rate and temperature dependency of } \\
\text { growth }\end{array}$ & DFT/Monte Carlo & [97] \\
\hline $\mathrm{Zr}(\mathrm{Hf}) \mathrm{O}_{2}$ & $\begin{array}{l}\text { Predict temperature dependency of growth } \\
\text { rate (Kinetics) }\end{array}$ & Monte Carlo & [95] \\
\hline $\mathrm{Cu} / \mathrm{CuO}$ & $\begin{array}{l}\text { Introduce new precursor } \\
\text { Predict mechanisms and growth }\end{array}$ & DFT & {$[48,174-176]$} \\
\hline $\mathrm{Ru}$ & Compare reactions of precursors & DFT & [177] \\
\hline $\mathrm{Y}_{2} \mathrm{O}_{3}$ & Predict chemisorption process & Mass balance & [161] \\
\hline
\end{tabular}


Table 2. Cont.

\begin{tabular}{|c|c|c|c|}
\hline Materials & Aspect of Study & Theoretical Method & References \\
\hline $\mathrm{SiC}$ & Introduce precursor & DFT & [178] \\
\hline $\mathrm{N} / \mathrm{A}$ & $\begin{array}{c}\text { Simulate growth rate based on chemisorption process } \\
\text { Describe growth mode } \\
\text { Characterize carrier gas flow } \\
\text { Model morphology evolution } \\
\text { Compare precursor exposure on 3D substrates } \\
\text { Predict cation ratios in ternary oxides }\end{array}$ & $\begin{array}{c}\text { Mass balance; LBM Monte } \\
\text { Carlo; DFT }\end{array}$ & {$[56,66,86,94,179,180]$} \\
\hline
\end{tabular}

(a)

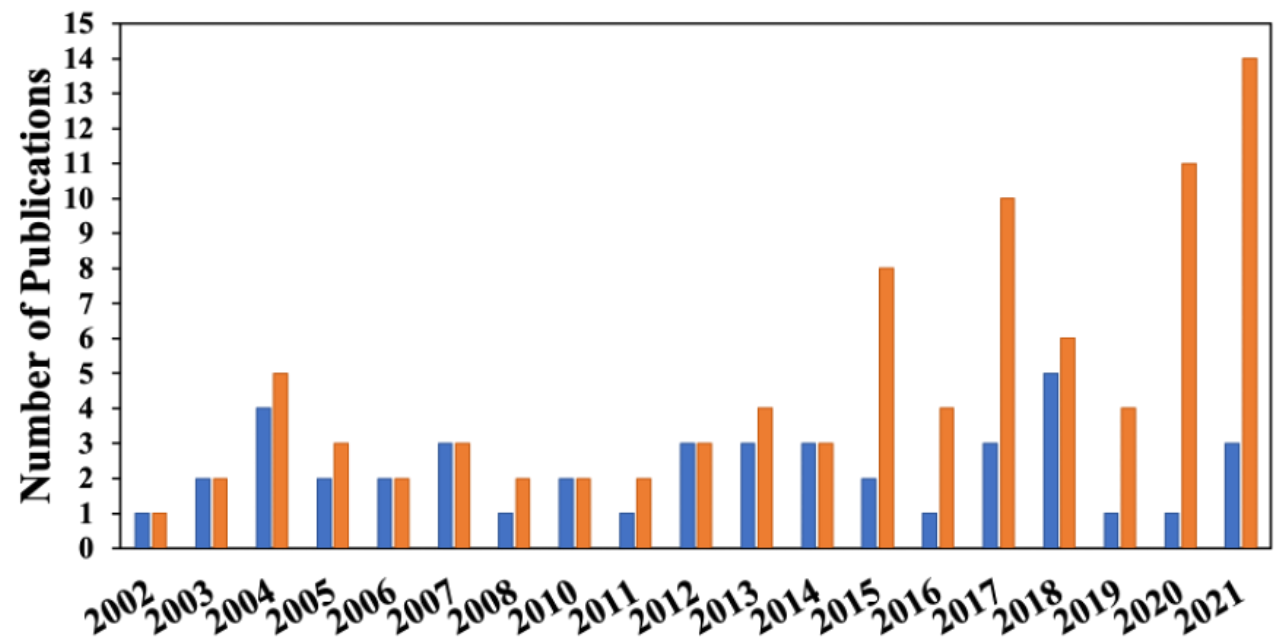

\section{- Theoretical Included Comined}

\section{Regions}

(b)

Number of Publications 13

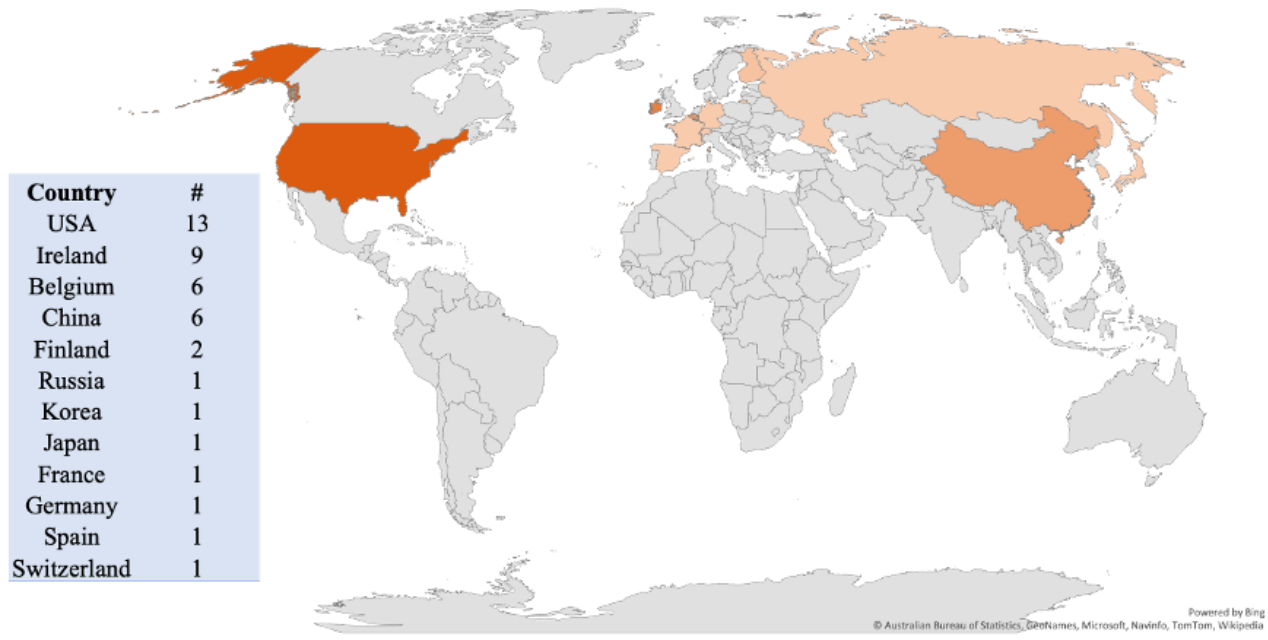

Figure 5. Illustration of the number of publications summarized in Table 2 categorized (a) per year between 2002 and 2021 and (b) per publication country. The search was performed with Web of Science using the following keywords: Atomic Layer Deposition and Theoretical. Irrelevant works were omitted and works combining experiments and theory are not covered in detail.

Figure 6a presents the percentage of articles on ALD thin film materials studied with theoretical methods. Most researchers have focused on $\mathrm{Al}_{2} \mathrm{O}_{3}$ thin films presumably due 
to the simple and well-understood reaction mechanism of TMA and water. In this figure, the "others" section includes the theoretically studied ALD materials of yttrium oxide, silicon oxide, and ruthenium. Figure $6 b-d$ visually categorize the research articles based on theoretical methods and ALD aspects (i.e., precursors, deposition characterization, and reaction mechanisms, respectively).
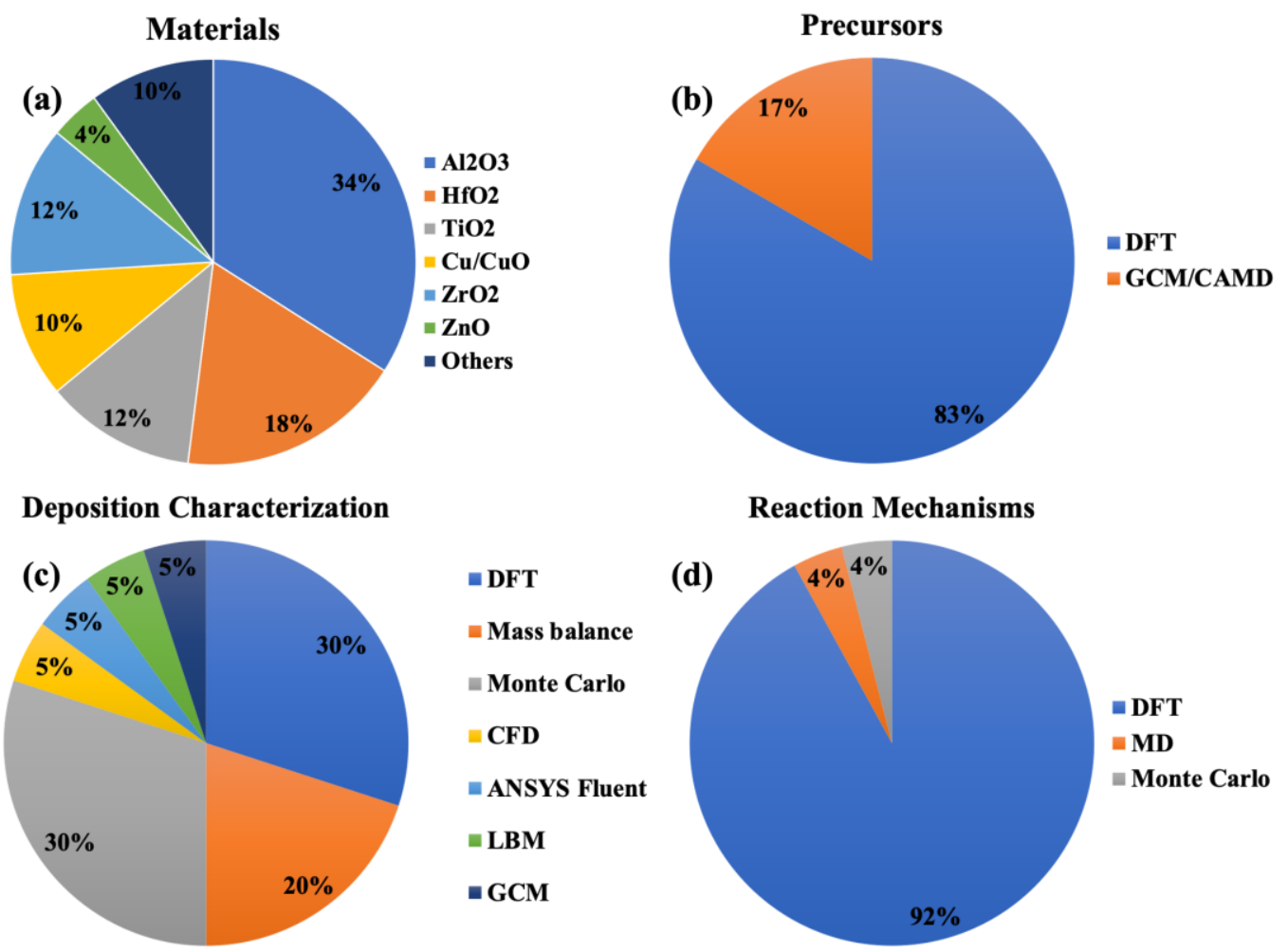

Figure 6. Theoretical studies of ALD categorized based on the theoretical method and (a) thin film material and the ALD aspect under study, i.e., (b) precursors, (c) deposition characterization, and (d) reaction mechanisms.

\subsection{Precursors}

First-principles theoretical methods can be used to select and optimize ALD precursors given any conditions. For instance, no experimental condition for ALD of silicon carbide (SiC) was known when Filatova et al. [178] performed DFT calculations to introduce the most promising precursors for this ALD system. They predicted that the combinations of disilane $\left(\mathrm{Si}_{2} \mathrm{H}_{6}\right)$, silane $\left(\mathrm{SiH}_{4}\right)$, or monochlorosilane $\left(\mathrm{SiH}_{3} \mathrm{Cl}\right)$ with ethyne $\left(\mathrm{C}_{2} \mathrm{H}_{2}\right)$, carbon tetrachloride $\left(\mathrm{CCl}_{4}\right)$, or trichloromethane $\left(\mathrm{CHCl}_{3}\right)$ would be the most promising materials for $\mathrm{ALD}$ of $\mathrm{SiC}$ at $400^{\circ} \mathrm{C}$. As of then, $\mathrm{SiC}$ was only deposited via high-temperature CVD, and that was how they validated their method [178]. Therefore, those materials and conditions for ALD were proposed without performing a single experiment, saving a huge amount of time and energy. Thus, theoretical techniques can be used in a stand-alone manner without experiments, making them very powerful methods.

In 2014, Jung et al. [145] studied a newly synthesized zirconium precursor for $\mathrm{ZrO}_{2}$ ALD on silicon and compared their results with a commonly used zirconium precursor. Aside from exploring the properties of the precursor and film growth, they performed DFT to examine the initial growth mechanism of $\mathrm{ZrO}_{2}$ on hydroxylated silicon. According to their DFT calculations, the new precursor would result in a lower growth rate due to steric hindrance but, at the same time, a more distinct fraction of a monolayer during one cycle [145].

Dey and Elliott [48] introduced a copper (I) carbene hydride using DFT calculations that acted both as a reducing agent and a precursor for $\mathrm{Cu}$ ALD. They proposed a $\mathrm{Cu}$ based reducing agent in case a co-deposition happened, which would be desirable as 
copper was still deposited [48]. In addition to Cu ALD [48,75,174], other materials have been studied through DFT, e.g., platinum [148], aluminum oxide [76,146,147], hafnium oxide [74,166,167], titanium oxide [77,169], and zirconium oxide [80,171]. Another study used DFT to design an aluminum ALD precursor by substituting one methyl in TMA and selectively decorating $\mathrm{Pt}$ nanoparticles by $\mathrm{AlO}_{\mathrm{x}}$ via ALD [76]. Yang et al. [76] showed that dimethylaluminum isopropoxide (DMAI) could be used as an ALD precursor, and they predicted the decomposition mechanism of DMAI with DFT [76]. Recently, Park et al. [166] compared two different hafnium precursors for ALD. DFT was used to predict that the cyclic precursor would result in a lower growth rate compared with the alkylamide precursor due to the low probability of final chemical adsorption of the bulky cyclic ligand on the surface [166].

When a decision needs to be made between two similar precursors, DFT can be used to compare different ALD precursors without performing any experiments. For instance, halide precursors have been compared with regard to thermodynamics and kinetics [169]. $\mathrm{Hu}$ and Turner [169] compared $\mathrm{TiI}_{4}$ and $\mathrm{TiCl}_{4}$ from different aspects. Their results revealed that the difference in bond strength between Ti-I and Ti-Cl would not lead to a considerable change in the kinetics of their reactions with water. In contrast, different bond strengths significantly affected the reaction thermodynamics [169]. Without performing a single experiment, one would choose $\mathrm{TiI}_{4}$ over $\mathrm{TiCl}_{4}$ when a film with less impurity and a lower ALD temperature is more favored; for instance, $\mathrm{TiI}_{4}$ would probably be a better precursor for $\mathrm{TiO}_{2}$ ALD on organic substrates compared with $\mathrm{TiCl}_{4}$.

Recently, Shahmohammadi et al. [100] developed a theoretical method to design novel precursor materials for ALD. First, they developed a GCM model to predict the thermodynamic properties (i.e., activity coefficients) of the functional groups of alreadyexisting ALD precursor materials such as tetrakis(dimethylamido)titanium (TDMAT), tetrakis (diethylamino) titanium (TDEAT), tetrakis (diethylamino) hafnium (TDEAH), and tetrakis (ethylmethylamino) hafnium (TEMAH). Then, using the estimated activity coefficients of those groups, they formulated a CAMD framework to optimally design novel precursor materials for ALD. Compared with the commercially available precursors, the most optimal designed precursors were predicted to have a $\sim 40 \%$ increase in the ALD growth rate [100]. The same GCM model was employed to quantify the water impurity in an ALD reactor, which will be discussed in the next section [101].

\subsection{Deposition Characterization}

Different theoretical models can be used to describe the growth rate in ALD. In 2003, Puurunen [66] derived a mathematical model based on mass balance to describe ALD growth rate as a function of growth chemistry. The chemistry of growth was defined as the size of the reactants and their chemisorption mechanism on the substrate. Using that model, if the size of the ligands is known, one can simulate the growth per cycle from any compound with a certain chemisorption mechanism. The chemisorption processes of ligand exchange, association, and dissociation were theoretically described for the adsorption of the precursor on the substrate. It was found that either a steric hindrance or a limited number of active sites on the substrate causes surface saturation. According to the author, the steric hindrance of ligands would lead to the growth rate being less than a monolayer per cycle [66]. In another article, the same model was applied to three ALD systems, i.e., $\mathrm{Al}_{2} \mathrm{O}_{3}$ from TMA and $\mathrm{H}_{2} \mathrm{O}$, Yttrium oxide $\left(\mathrm{Y}_{2} \mathrm{O}_{3}\right)$ from $\mathrm{Y}(\text { thd })_{3}$ and $\mathrm{O}_{3}$ (thd $=2,2,6,6$ tetramethyl-3,5-heptanedionate), and $\mathrm{TiO}_{2}$ from $\mathrm{TiCl}_{4}$ and $\mathrm{H}_{2} \mathrm{O}$. Based on that report, the ligand exchange would occur with all $\mathrm{OH}$ groups in the TMA $/ \mathrm{H}_{2} \mathrm{O}$ process and with one or more $\mathrm{OH}$ groups in the $\mathrm{Y}(\mathrm{thd})_{3} / \mathrm{O}_{3}$ and $\mathrm{TiCl}_{4} / \mathrm{H}_{2} \mathrm{O}$ processes. Moreover, in all three systems, the steric hindrance of ligands likely defined the saturation [161]. A year later, the same author theoretically described random deposition as an ALD growth mode [56]. According to that research, random deposition and the growth rate value related the surface coverage to the surface fractions and the coverage of different layers. The surface fraction 
was defined as the difference between coverages of a layer and the previous layer, whereas the sum of those fractions resulted in the surface coverage [56].

Murray and Elliott [180] performed a comprehensive DFT investigation on ALD from 17 different metal precursors. Using hydrolysis models, they were able to predict the reactivity and stoichiometry of metal cation ratios in a variety of ternary oxides grown by ALD [180]. In another article, Elliot [78] developed a theoretical framework based on DFT to predict the growth rate and the intermediates of the reaction as well as their concentration in an $\mathrm{Al}_{2} \mathrm{O}_{3}$ ALD system. The well-known TMA and water system was employed for that study. The DFT analysis was performed with respect to the surface coverage of the intermediates, such as $\mathrm{CH}_{3}$ and $\mathrm{H}$, and the effect of temperature as a processing condition was studied. According to the author, the higher processing temperature caused a higher concentration of hydrogen intermediates, reducing the growth rate. In addition, the lower temperature limited the mobility of hydrogen atoms, which decreased the growth rate in the system of that study [78].

In another TMA/water study by Puurunen [73], the growth rate was shown to quantitatively correlate to the concentration of hydroxyl groups on the surface before the TMA reaction. Based on the results of that study, the correlation parameters depended on the precursor chemisorption and steric hindrance [73]. The temperature dependency of the growth rate was also discussed in Puurunen's study, where the temperature effect was related to the concentration of hydroxyl groups on the surface. As the substrate temperature increased, the concentration of surface hydroxyl groups decreased, which in turn reduced the growth rate [73]. The finding was in agreement with the previously discussed study by Elliot [78]. Both of those studies considered $\mathrm{Al}_{2} \mathrm{O}_{3}$ ALD using TMA and water, while, recently, Seo et al. [163] employed DFT to study the effect of different oxidizers (i.e., $\mathrm{H}_{2} \mathrm{O}_{2}$ and $\mathrm{O}_{3}$ ) reacting with TMA. According to their results, the molecular reactivity toward ALD of $\mathrm{Al}_{2} \mathrm{O}_{3}$ on a $\mathrm{CH}$-terminated surface at low deposition temperatures for the three oxidizing agents was expected to be $\mathrm{H}_{2} \mathrm{O}<\mathrm{H}_{2} \mathrm{O}_{2}<\mathrm{O}_{3}$. Moreover, one $\mathrm{H}_{2} \mathrm{O}$ molecule was required to complete the reaction, whereas this number for both $\mathrm{O}_{3}$ and $\mathrm{H}_{2} \mathrm{O}_{2}$ was 2 [163]. DFT was used in another research study to investigate ALD-grown copper oxide nanoclusters on a porphyrin, supporting their similar reactivity characteristics with $\mathrm{Cu}$-exchanged zeolites toward direct methane-to-methanol oxidation in a stepped conversion process [175].

One of the well-established numerical techniques extensively used in different areas is Monte Carlo simulation. Monte Carlo simulation was previously performed to explain ALD film growth in nanopores [96]. In that study, uniform film growth was observed up to 75 cycles, beyond which the film grew non-uniformly. At higher cycles, a thicker film was observed at the pore edge compared with the pore center, which was attributed to increasing the resistance to precursor diffusion at the pore mouth and the precursor depletion in the central regions with increasing the cycle numbers [96]. In 2018, Weckman et al. [97] performed a comprehensive study on the overall growth and surface chemistry of $\mathrm{ZnO}$ ALD by implementing a DFT calculation into a kMC model. According to the authors, the temperature dependency of film growth was in agreement with experimental data, while the growth rate per cycle was overestimated with simulation. Based on their report, the film growth in the reported system was low at lower temperatures, which was attributed to the high activation energy required to eliminate ethyl ligands of the precursor, which in turn caused impurities in the film. However, those barriers would be overcome at higher temperatures, resulting in a higher growth rate [97].

Moreover, the gas flow and temperature profile in ALD have been studied experimentally and theoretically. Burgess et al. [162] used CFD codes to simulate the gas flow and temperature profile in the $\mathrm{AL}_{2} \mathrm{O}_{3}$ and $\mathrm{HfO}_{2} \mathrm{ALD}$ systems. They employed quantum calculations to identify reaction pathways and energies in both systems [162]. The gas flow and surface reactions in $\mathrm{Al}_{2} \mathrm{O}_{3}$ ALD using TMA and water were studied using 3D transient numerical models. The predicted growth rate under different ALD conditions (i.e., temperature and precursor purging time) was compared with experimental values. Slightly higher growth rates were predicted compared with the experimental results. The 
longer purge times at lower temperatures would result in closer agreement between the experimental and predicted growth rates. One interesting observation of that work was that the growth rate was dependent on the location of the sample in their ALD reactor, and the samples near the inlet of the reactor had a higher growth rate than those near the outlet [149]. Although their results showed good agreement between experiments and simulations, they only considered one full ALD cycle in their numerical study. A previous study suggested that after a specific number of ALD cycles where a rather thick film is formed, the growth mechanism and the growth rate may change since the effect of the substrate is diminished [6]. Pan et al. [86] compared two common LBM models to characterize the carrier gas flow in ALD: the lattice Bhatnagar-Gross-Krook (LBGK) and two-relaxation-time (TRT) models. According to their results, the TRT model was more reliable regarding stability, while the LBGK model was better in terms of computational efficiency [86].

Monte Carlo simulation is also applicable in implementing the kinetics of ALD. For example, Deminsky et al. [95] performed kMC simulation to study the temperature dependency of the growth rate and reported its slight decrease between 200 and $600{ }^{\circ} \mathrm{C}$ in $\mathrm{Zr}(\mathrm{Hf}) \mathrm{O}_{2}$ ALD. The observed temperature dependency of the growth rate was reported to be in agreement with experimental data and due to the steric repulsion between chemisorbed groups and adsorbed precursor molecules [95]. This is in line with another work, where the researchers used CAMD to design novel precursor materials for ALD, and the predicted growth rates displayed temperature dependency [100].

The morphology evolution of the films produced by ALD can be modeled and studied through Monte Carlo simulation. In a previous study, amorphous films deposited by ALD were examined with Monte Carlo simulation [94]. Based on the results, steric hindrance would delay the linear growth [94]. In addition, 3D Monte Carlo simulation has been used to determine the film thickness and sticking coefficients of TMA and bis-diethyl aminosilane (BDEAS) precursors in high-aspect-ratio 3D substrates [93]. In another work, Cremers et al. [179] reported the results of 3D Monte Carlo simulation in ALD on different large geometries, i.e., pillars versus holes. According to the authors, much less precursor exposure is needed for conformal ALD on pillars than holes, which, as a result, makes arrays of pillars more appropriate for ALD [179].

A recent report from the authors employed the GCM and ASST to quantify the impurity in an ALD reactor [101] reported earlier. When PMMA and a silicon reference were present in the same ALD reactor, the $\mathrm{TiO}_{2}$ growth rate on silicon was higher than stand-alone silicon. This elevated growth rate had been observed experimentally and was attributed to the released water molecules from PMMA pores [6]. With the help of the theoretical methods, the precise amount of water vapor from PMMA was calculated and confirmed the previously reported hypothesis. The predicted growth rate on the silicon reference was in agreement with the experimental data. The model also showed that the moles of water molecules acting as the second co-reactant of ALD decreased with increasing the number of ALD cycles [101]. This decreasing trend had been observed with experiments as well [6].

\subsection{Mechanisms}

The reaction mechanism happening in the $\mathrm{Al}_{2} \mathrm{O}_{3}$ ALD system using TMA and water has been studied theoretically to determine thermodynamically favorable pathways at various stages of ALD [157-159,164,165]. DFT cluster models have been used to predict reaction energetics and transition state structures for adsorption and a single ligand exchange during both the TMA and water half-reactions. Both half-cycle reactions are reported to be exothermic, happening through the formation of an Al-O Lewis acid-base complex followed by $\mathrm{CH}_{4}$ formation [164]. Another article was focused on atomic-scale models to investigate the reaction steps involved in the growth of $\mathrm{Al}_{2} \mathrm{O}_{3} \mathrm{ALD}$, especially precursor adsorption and by-product elimination [165]. Recently, reaction mechanisms between TMA 
and $\mathrm{O}_{3}$ were investigated using DFT. Some plausible intermediates of those reactions were found to be methoxy, formate, bicarbonate, and hydroxyl intermediates [160].

The dissociation of water molecules, when adsorbed on the substrate, hydroxylates the surface. Thus, when studying reaction mechanisms, the $\mathrm{OH}$ groups should be considered. DFT is used to study in detail energetics of the initial reaction pathways on the hydroxylated surface during the TMA pulse. TMA is reported to adsorb exothermically on the surface, reacting with the hydroxylated $\mathrm{Al}_{2} \mathrm{O}_{3}$ surface through ligand exchange reactions [157]. Travis and Adomaitis [158] used existing energetics data to determine kinetic parameters using statistical thermodynamics and absolute reaction rate theory. They presented a surface reaction kinetics and film growth model for the TMA half-reactions of $\mathrm{Al}_{2} \mathrm{O}_{3} \mathrm{ALD}$ on a range of surfaces from bare to full hydroxylated states. According to their results, the reaction pathway differed if the surface was bare or hydroxylated, and maximum ALD growth only occurred at an initially saturating hydroxyl group density [158]. Brown et al. [83] performed $\mathrm{MD}$ on $\mathrm{Al}_{2} \mathrm{O}_{3} \mathrm{ALD}$, focusing on dissociation reactions. Based on their results, the studied variables, such as growth rate and surface roughness, were in close agreement with the experimentally reported values. However, the previous studies that only considered the ligand exchange reactions achieved less agreement with the experimental data [181].

Metal alkoxides were reported to be used as both hafnium and oxygen precursors in ALD. Mui and Musgrave [74] predicted the chemical mechanism of $\mathrm{HfO}_{2}$ ALD using DFT calculations, in which they examined Tetraethoxyl Hafnium $\left(\mathrm{Hf}(\mathrm{OEt})_{4}\right)$ as both a precursor and an oxidizer. They studied different reaction pathways that would affect the ALD growth rate. According to the authors, incomplete surface elimination most likely led to carbon contamination and competed kinetically with the ligand exchange half-reactions. Additionally, the use of $\mathrm{Hf}(\mathrm{OEt})_{4}$ as the oxygen precursor was not advantageous as it violated the self-limiting characteristic of ALD [74]. The halide hafnium precursor was used in another work to examine the mechanisms of half-reactions happening in $\mathrm{HfO}_{2}$ ALD. It was reported that the adsorption energy and the preferred adsorption sites for metal precursors depended on the water coverage. That is, increasing the water coverage would lead to higher interaction between the metal precursor and multiple surface adsorption sites [167]. Another study reported the effect of cluster size on the formation of the $\mathrm{HfCl}_{4}$ complex during the precursor half-reaction [70].

The densification process in $\mathrm{HfO}_{2}$ ALD on $\mathrm{SiO}_{2}$ was studied through combined DFT and $\mathrm{kMC}$ [168]. The introduced possible densification reactions, which impacted growth evolution, were nucleation, the "inter-side" reaction, and the "on-site" reaction. The authors compared the simulation results of surface coverage to the experimental data up to 10 ALD cycles. They concluded that considering the densification reactions was the only condition that caused the agreement with experiments [168]. A year later, another group used DFT to study the reactions happening in $\mathrm{HfO}_{2}$ ALD [79]. They reported a detailed mechanism for that ALD system from tetrakis(dimethylamido)hafnium and water. Based on calculated activation energies, multiple proton diffusions from the surface to amide ligands and rotation of the protonated amine are more energetically favorable than ligand elimination in the initial stage. Thus, multiple proton diffusions to the amide ligands happen before the protonated amine ligands desorb. When the precursor was adsorbed on the surface, multiple protons diffused to amine ligands. That freed up hafnium to bond with oxygen, which had already been freed due to protonation and desorption of ligands and become five-coordinated. Then, hafnium became four-coordinated upon further ligand elimination. Hafnium became more highly coordinated as more ligands were eliminated, forming bonds with more oxygens and causing densification. The remaining ligands exchanged with hydroxyl groups during the water pulse, preparing the surface for the next precursor pulse [79].

$\mathrm{Hu}$ and Turner [77] employed DFT to investigate, in detail, the initial surface reactions of $\mathrm{TiO}_{2}$ ALD from $\mathrm{TiCl}_{4}$ and water. They studied different reactive groups of the $\mathrm{SiO}_{2}$ surface as the substrate, i.e., isolated hydroxyl groups, adjacent hydrogen-bonded hydroxyl 
groups, and surface oxygen bridges. According to their report, all the investigated surfaces were reactive toward $\mathrm{TiCl}_{4}$, where different intermediate species with different activation barriers were formed on each surface [77]. Later on, DFT was employed to compare the initial growth mechanisms in $\mathrm{ALD}$ of $\mathrm{TiO}_{2}$ and $\mathrm{ZrO}_{2}$ on $\mathrm{SiOH}$ surfaces using cycloheptatrienyl (CHT)-cyclopentadienyl (Cp) precursors [170,172]. According to the authors' DFT calculations, the reactions happened through similar pathways in both metal oxides, where one hydrogen atom from the surface was transferred to the precursor ligand (Figure 7 , reprinted with permission from reference [170]). However, the $\mathrm{Zr}$ precursor adsorption was exothermic and thus energetically favorable, whereas that of the Ti precursor was endothermic and thermodynamically unfavorable. The authors reported this difference to be a reason why an ALD window had been experimentally observed for $\mathrm{ZrO}_{2}$ growth and not for $\mathrm{TiO}_{2}$ growth [170]. The same researchers proposed initial reaction pathways for an ansa-metallocene $\mathrm{Zr}$ precursor $\left(\left(\mathrm{Cp}_{2} \mathrm{CMe}_{2}\right) \mathrm{ZrMe}_{2}\right)$, where the steric hindrance of the large ligand prevented the reaction from occurring through chemisorption, and it happened due to the dispersion effect of the bulky ligand [173].
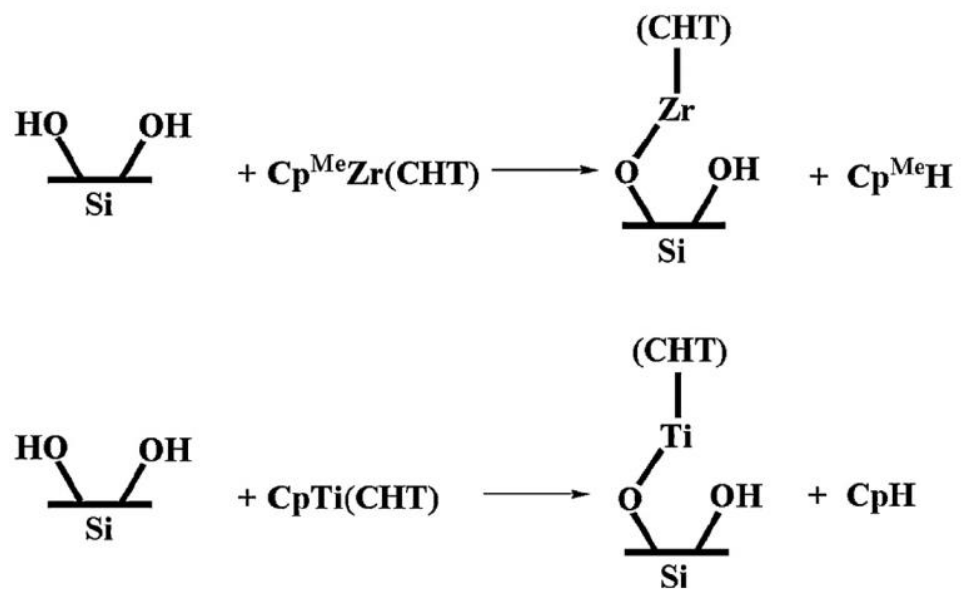

Figure 7. Surface reactions of $\mathrm{Cp}^{\mathrm{Me}} \mathrm{Zr}(\mathrm{CHT})$ and $\mathrm{CpTi}(\mathrm{CHT})$ on the $\mathrm{SiOH}$ surface (reprinted with permission from reference [170]).

Han et al. [171] studied the initial growth mechanisms in $\mathrm{ZrO}_{2}$ ALD on hydroxylated $\mathrm{SiO}_{2}$ substrates by DFT. The intermediate complexes formed after each half-reaction of $\mathrm{ZrCl}_{4}$ and water were similar to the ones shown in Table 1. Furthermore, they reported that increasing the temperature would increase the precursor desorption and sub-monolayer growth. Another research study was performed on a similar system. Cui and Ren [80] investigated fourteen possible pathways of chlorine loss reactions in $\mathrm{ZrO}_{2}$ ALD using $\mathrm{ZrCl}_{4}$ and water through DFT. They reported that the $\mathrm{HCl}$ by-product did not prefer to self-eliminate throughout the process. Thus, eliminating chloride contaminations should be considered in that ALD system. Moreover, they discussed temperature effects on chlorine loss reactions, where the self-elimination of $\mathrm{HCl}$ was the dominant pathway at a lower temperature. At elevated temperatures, although the self-elimination of $\mathrm{HCl}$ was still favorable, hydrolysis was the dominant pathway due to the decrease in hydroxyl groups [80].

In addition to metal oxides, the mechanisms happening in metal ALD have also been investigated through DFT. For instance, Karasulu et al. [148] investigated platinum ALD on graphene using DFT. As a result, they were able to minimize the experimental procedures for process development and revealed that graphene oxide is an effective seed layer to obtain a uniform continuous $\mathrm{Pt}$ thin film. Ab initio DFT MD simulations were also helpful for investigating the thermal stability of simulation models [148]. Another interesting study used DFT to compare the reactions of two precursors in ruthenium ALD on different ruthenium surfaces [177]. The authors' comparison between reactions on various substrates proved that a surface with a high surface energy and a complex 
topology, i.e., a surface with more defective sites for the adsorption and reaction, was the best substrate for ALD. Moreover, the presence of hydrogen atoms on the surface would prevent precursor adsorption [177].

In 2015, Hu et al. [75] studied the ALD of Copper(II) acetylacetonate $\left(\mathrm{Cu}(\mathrm{acac})_{2}\right)$ on $\mathrm{Cu}(110)$ substrates, and investigated initial surface reactions of the copper precursor through DFT calculations and reactive molecular dynamics (RMD) simulations. Based on their results, the dissociation of $\mathrm{Cu}(\mathrm{acac})_{2}$ easily happened on $\mathrm{Cu}$ atoms, while the acac ligand could dissociate on both copper and copper oxide surfaces. Their DFT calculations revealed the sequential dissociation and reduction of the $\mathrm{Cu}(\mathrm{acac})_{2}$ precursor on the copper substrate $\left(\mathrm{Cu}(\mathrm{acac})_{2}-\mathrm{Cu}(\mathrm{acac})-\mathrm{Cu}\right)$, which was in line with the reaction pathways they observed through RMD. Their RMD simulations revealed that the copper-rich surfaces were more reactive toward the precursor's decomposition. They also reported that the atomic hydrogen was more reactive toward the precursors with hydrocarbon ligands than ozone or water as co-reactants [75]. Two years later, the mechanisms of metal ALD chemistry on an atomic scale were investigated through DFT [174]. The work by Elliot et al. [174] supported the reduction of a $\mathrm{Cu}(\mathrm{acac})_{2}$ precursor on $\mathrm{Cu}$ substrates, which had been reported earlier [75]. Another DFT study investigated the transmetalation reactions as the mechanism for $\mathrm{Cu}$ ALD using diethylzinc $\left(\mathrm{ZnEt}_{2}\right)$ as the reducing agent [176]. The most thermodynamically favorable gas-phase reactions in both the precursor and co-reagent pulses are presented in Figure 8 (reprinted from reference [176]). The letter L in Figure 8 refers to the ligands of the reagents, meaning the reactions were generalized for commonly used $\mathrm{Cu}$ precursors, irrespective of which was used, while copper dimethyl-2-propoxide $\left(\mathrm{Cu}(\mathrm{dmap})_{2}\right)$ was reported to be the best one [176].

\section{Precursor Pulse}

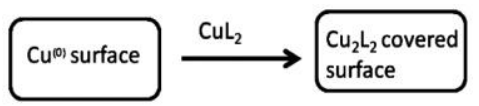

(a)

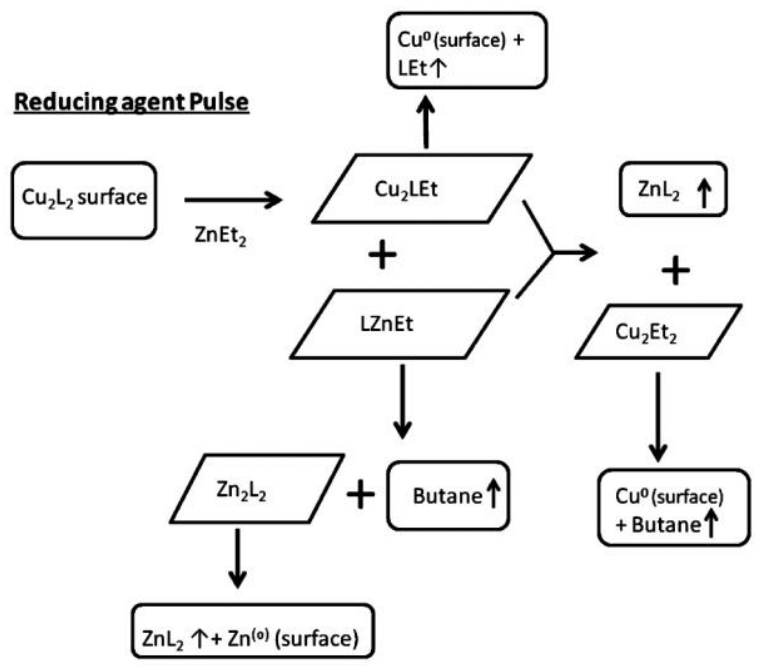

(b)

Figure 8. Flowcharts depicting possible ALD mechanisms for (a) a precursor pulse and (b) a reducingagent pulse. Rectangular shapes denote starting reagents and end products, and slanted boxes denote intermediates. The upward arrows represent desorption of volatile species (reprinted with permission from [176]). 


\section{Summary, Insights, and Future Challenges}

In this review, all theoretical methods that have been employed so far to study ALD are discussed. The fundamental and ab initio (first-principles) techniques such as DFT are used to predict atomic behavior at the micro-level. These methods provide detailed information on atomic interactions without depending on experiments since they do not require initial data to be obtained. However, they are time-consuming and can become very expensive. On the contrary, macro-level methods such as CAMD are much faster and more cost-efficient than the aforementioned ones. These methods predict the optimal chemical molecules based on information about building blocks (functional groups) rather than atoms and can be used for reverse engineering. However, the main drawback of these techniques is the necessity of experimental data. For instance, one would need the properties of groups of molecules to use CAMD, requiring experimental data. Thus, whenever there is a lack of experimental data, the ab initio methods are useful, but if the experimental data are available, it would be more efficient to use reverse engineering methods.

Most of the researchers have so far focused on varying the operating temperature to theoretically predict the growth, film properties, and reaction mechanisms in an ALD system. However, the temperature is not the only factor affecting ALD reactions. Other factors, such as the substrate, gas flow, reactor design, and adsorbate-adsorbate and adsorbate-adsorbent interactions, affect the predicted mechanisms happening in ALD reactions. Those factors may be varied through computational methods to better predict the behavior of different ALD processes. In addition, most of the theoretical research articles on ALD so far have focused on the processes on inorganic substrates. However, since more and more experimental ALD studies are being performed on organic substrates, such as polymers and biomaterials, the actual growth behavior and reaction mechanisms on these materials are largely unknown. Due to the nature of organic materials, it would be highly complicated and challenging to predict the growth behavior, thin film characteristics, and reaction mechanisms on those substrates. We hope to see such interesting studies from theoreticians in the future to better assist in the design of experiments in those fields.

Author Contributions: Conceptualization, M.S. and R.M.; investigation, M.S.; resources, C.G.T.; writing-original draft preparation, M.S.; writing—review and editing, R.M., C.S., U.M.D., C.G.T.; visualization, M.S.; supervision, U.M.D., C.G.T.; project administration, U.M.D., C.G.T.; funding acquisition, C.G.T. All authors have read and agreed to the published version of the manuscript.

Funding: This research was partially funded by National Science Foundation (NSF 1309114).

Acknowledgments: Partial support by the National Science Foundation, NSF 1309114, is gratefully acknowledged. Figure 1 was created with BioRender.com.

Conflicts of Interest: The authors declare no conflict of interest.

\section{References}

1. Ritala, M.; Leskelä, M. Chapter 2-Atomic layer deposition. In Handbook of Thin Films; Singh Nalwa, H.B.T.-H., Ed.; Academic Press: Burlington, VT, USA, 2002; pp. 103-159. ISBN 978-0-12-512908-4.

2. Puurunen, R.L. A short history of atomic layer deposition: Tuomo Suntola's atomic layer epitaxy. Chem. Vap. Depos. 2014, 20, 332-344. [CrossRef]

3. George, S.M. Atomic layer deposition: An overview. Chem. Rev. 2010, 110, 111-131. [CrossRef] [PubMed]

4. Leskelä, M.; Ritala, M. Atomic Layer Deposition Chemistry: Recent Developments and Future Challenges. Angew. Chemie - Int. Ed. 2003, 42, 5548-5554. [CrossRef]

5. Oviroh, P.O.; Akbarzadeh, R.; Pan, D.; Coetzee, R.A.M.; Jen, T.-C. New development of atomic layer deposition: Processes, methods and applications. Sci. Technol. Adv. Mater. 2019, 20, 465-496. [CrossRef] [PubMed]

6. Shahmohammadi, M.; Pensa, E.; Bhatia, H.; Yang, B.; Jursich, G.; Takoudis, C.G. Enhancing the surface properties and functionalization of polymethyl methacrylate with atomic layer-deposited titanium(IV) oxide. J. Mater. Sci. 2020, 55, 17151-17169. [CrossRef]

7. Knoops, H.C.M.; Potts, S.E.; Bol, A.A.; Kessels, W.M.M. Atomic Layer Deposition. In Handbook of Crystal Growth: Thin Films and Epitaxy; Kuech, T., Ed.; Elsevier: Amsterdam, The Netherlands, 2015; Volume 3, pp. 1101-1134. ISBN 9780444633057.

8. Hagen, D.J.; Pemble, M.E.; Karppinen, M. Atomic layer deposition of metals: Precursors and film growth. Appl. Phys. Rev. 2019, 6, 41309. [CrossRef] 
9. Johnson, R.W.; Hultqvist, A.; Bent, S.F. A brief review of atomic layer deposition: From fundamentals to applications. Mater. Today 2014, 17, 236-246. [CrossRef]

10. Shahmohammadi, M.; Yang, B.; Takoudis, C.G. Applications of Titania Atomic Layer Deposition in the Biomedical Field and Recent Updates. Am. J. Biomed. Sci. Res. 2020, 8, 465-468. [CrossRef]

11. Tao, Q.; Jursich, G.; Takoudis, C. Selective atomic layer deposition of $\mathrm{HfO}_{2}$ on copper patterned silicon substrates. Appl. Phys. Lett. 2010, 96, 192105. [CrossRef]

12. Sheng, J.; Han, K.-L.; Hong, T.; Choi, W.-H.; Park, J.-S. Review of recent progresses on flexible oxide semiconductor thin film transistors based on atomic layer deposition processes. J. Semicond. 2018, 39, 11008. [CrossRef]

13. Majumder, P.; Jursich, G.; Takoudis, C. Structural phase transformation of $\mathrm{Y}_{2} \mathrm{O}_{3}$ doped $\mathrm{HfO}_{2}$ films grown on Si using atomic layer deposition. J. Appl. Phys. 2009, 105, 104106. [CrossRef]

14. Meng, X.; Yang, X.; Sun, X. Emerging applications of atomic layer deposition for lithium-ion battery studies. Adv. Mater. 2012, 24, 3589-3615. [CrossRef] [PubMed]

15. Jung, Y.S.; Cavanagh, A.S.; Dillon, A.C.; Groner, M.D.; George, S.M.; Lee, S.-H. Enhanced stability of LiCoO $\mathrm{O}_{2}$ cathodes in lithium-ion batteries using surface modification by atomic layer deposition. J. Electrochem. Soc. 2009, 157, A75. [CrossRef]

16. Cao, Y.-Q.; Wang, S.-S.; Liu, C.; Wu, D.; Li, A.-D. Atomic layer deposition of $\mathrm{ZnO} / \mathrm{TiO}_{2}$ nanolaminates as ultra-long life anode material for lithium-ion batteries. Sci. Rep. 2019, 9, 1-9. [CrossRef]

17. Lin, Y.-C.; Chung, V.P.J.; Santhanam, S.; Mukherjee, T.; Fedder, G.K. Sidewall Metallization on CMOS MEMS by Platinum ALD Patterning. J. Microelectromechanical Syst. 2020, 29, 978-983. [CrossRef]

18. Fraga, M.; Pessoa, R. Progresses in Synthesis and Application of SiC Films: From CVD to ALD and from MEMS to NEMS Micromachines 2020, 11, 799. [CrossRef]

19. Vulpe, S.; Nastase, F.; Dragoman, M.; Dinescu, A.; Romanitan, C.; Iftimie, S.; Moldovan, A.; Apostol, N. Physical properties of the ferroelectric capacitors based on Al-doped $\mathrm{HfO}_{2}$ grown via Atomic Layer Deposition on Si. Appl. Surf. Sci. 2019, 483, 324-333. [CrossRef]

20. Fang, C.; Wang, M.; Han, P.; Cao, Y.-Q.; Wu, D.; Li, A.-D. High-Performance MIM Capacitors Using Zr-Sn-Ti-O Dielectrics Derived from Atomic Layer Deposition. IEEE Electron. Device Lett. 2019, 40, 682-685. [CrossRef]

21. Shim, J.H.; Chao, C.-C.; Huang, H.; Prinz, F.B. Atomic layer deposition of yttria-stabilized zirconia for solid oxide fuel cells. Chem. Mater. 2007, 19, 3850-3854. [CrossRef]

22. Liu, C.; Wang, C.; Kei, C.; Hsueh, Y.; Perng, T. Atomic layer deposition of platinum nanoparticles on carbon nanotubes for application in proton-exchange membrane fuel cells. Small 2009, 5, 1535-1538. [CrossRef]

23. Li, Y.K.; Choi, H.J.; Kim, H.K.; Chean, N.K.; Kim, M.; Koo, J.; Jeong, H.J.; Jang, D.Y.; Shim, J.H. Nanoporous silver cathodes surface-treated by atomic layer deposition of $\mathrm{Y}: \mathrm{ZrO}_{2}$ for high-performance low-temperature solid oxide fuel cells. J. Power Sources 2015, 295, 175-181. [CrossRef]

24. Wang, C.; Zhao, D.; Grice, C.R.; Liao, W.; Yu, Y.; Cimaroli, A.; Shrestha, N.; Roland, P.J.; Chen, J.; Yu, Z. Low-temperature plasma-enhanced atomic layer deposition of tin oxide electron selective layers for highly efficient planar perovskite solar cells. $J$. Mater. Chem. A 2016, 4, 12080-12087. [CrossRef]

25. Standridge, S.D.; Schatz, G.C.; Hupp, J.T. Toward plasmonic solar cells: Protection of silver nanoparticles via atomic layer deposition of TiO2. Langmuir 2009, 25, 2596-2600. [CrossRef] [PubMed]

26. Dong, X.; Fang, X.; Lv, M.; Lin, B.; Zhang, S.; Ding, J.; Yuan, N. Improvement of the humidity stability of organic-inorganic perovskite solar cells using ultrathin $\mathrm{Al}_{2} \mathrm{O}_{3}$ layers prepared by atomic layer deposition. J. Mater. Chem. A 2015, 3, 5360-5367. [CrossRef]

27. Sheng, J.; Park, E.J.; Shong, B.; Park, J.-S. Atomic layer deposition of an indium gallium oxide thin film for thin-film transistor applications. ACS Appl. Mater. Interfaces 2017, 9, 23934-23940. [CrossRef]

28. Lim, S.J.; Kwon, S.; Kim, H.; Park, J.-S. High performance thin film transistor with low temperature atomic layer deposition nitrogen-doped ZnO. Appl. Phys. Lett. 2007, 91, 183517. [CrossRef]

29. Kwon, S.; Bang, S.; Lee, S.; Jeon, S.; Jeong, W.; Kim, H.; Gong, S.C.; Chang, H.J.; Park, H.; Jeon, H. Characteristics of the ZnO thin film transistor by atomic layer deposition at various temperatures. Semicond. Sci. Technol. 2009, 24, 35015. [CrossRef]

30. Choi, J.H.; Jung, C.H.; Hwang, I.T.; Choi, J.H. Preparation and characterization of crosslinked poly(butylene adipate-coterephthalate)/polyhedral oligomeric silsesquioxane nanocomposite by electron beam irradiation. Radiat. Phys. Chem. 2013, 82, 100-105. [CrossRef]

31. Narayan, R.J.; Adiga, S.P.; Pellin, M.J.; Curtiss, L.A.; Stafslien, S.; Chisholm, B.; Monteiro-Riviere, N.A.; Brigmon, R.L.; Elam, J.W. Atomic layer deposition of nanoporous biomaterials. Mater. Today 2010, 13, 60-64. [CrossRef]

32. Skoog, S.A.; Elam, J.W.; Narayan, R.J. Atomic layer deposition: Medical and biological applications. Int. Mater. Rev. 2013, 58, 113-129. [CrossRef]

33. Narayan, R.J.; Monteiro-Riviere, N.A.; Brigmon, R.L.; Pellin, M.J.; Elam, J.W. Atomic layer deposition of TiO 2 thin films on nanoporous alumina templates: Medical applications. JOM 2009, 61, 12-16. [CrossRef]

34. Bishal, A.K.; Sukotjo, C.; Jokisaari, J.R.; Klie, R.F.; Takoudis, C.G. Enhanced Bioactivity of Collagen Fiber Functionalized with Room Temperature Atomic Layer Deposited Titania. ACS Appl. Mater. Interfaces 2018, 10, 34443-34454. [CrossRef] [PubMed] 
35. Xie, X.; Rieth, L.; Caldwell, R.; Diwekar, M.; Tathireddy, P.; Sharma, R.; Solzbacher, F. Long-Term Bilayer Encapsulation Performance of Atomic Layer Deposited $\mathrm{Al}_{2} \mathrm{O}_{3}$ and Parylene $\mathrm{C}$ for Biomedical Implantable Devices. IEEE Trans. Biomed. Eng. 2013, 60, 2943-2951.

36. Nazarov, D.V.; Smirnov, V.M.; Zemtsova, E.G.; Yudintceva, N.M.; Shevtsov, M.A.; Valiev, R.Z. Enhanced osseointegrative properties of ultra-fine-grained titanium implants modified by chemical etching and atomic layer deposition. ACS Biomater. Sci. Eng. 2018, 4, 3268-3281. [CrossRef]

37. Liu, L.; Bhatia, R.; Webster, T.J. Atomic layer deposition of nano- $\mathrm{TiO}_{2}$ thin films with enhanced biocompatibility and antimicrobial activity for orthopedic implants. Int. J. Nanomedicine 2017, 12, 8711-8723. [CrossRef] [PubMed]

38. Devlin-Mullin, A.; Todd, N.M.; Golrokhi, Z.; Geng, H.; Konerding, M.A.; Ternan, N.G.; Hunt, J.A.; Potter, R.J.; Sutcliffe, C.; Jones, E. Atomic layer deposition of a silver nanolayer on advanced titanium orthopedic implants inhibits bacterial colonization and supports vascularized de novo bone ingrowth. Adv. Healthc. Mater. 2017, 6, 1700033. [CrossRef] [PubMed]

39. Chang, S.; Selvaraj, S.K.; Choi, Y.-Y.; Hong, S.; Nakhmanson, S.M.; Takoudis, C. Atomic layer deposition of environmentally benign SnTiOx as a potential ferroelectric material. J. Vac. Sci. Technol. A Vacuum, Surfaces, Film. 2016, 34, 01A119. [CrossRef]

40. Koveshnikov, S.; Goel, N.; Majhi, P.; Wen, H.; Santos, M.B.; Oktyabrsky, S.; Tokranov, V.; Kambhampati, R.; Moore, R.; Zhu, F. In $0.53 \mathrm{Ga} 0.47 \mathrm{As}$ based metal oxide semiconductor capacitors with atomic layer deposition $\mathrm{ZrO}_{2}$ gate oxide demonstrating low gate leakage current and equivalent oxide thickness less than $1 \mathrm{~nm} . A p P h L$ 2008, 92, 222904.

41. Darwish, G.; Huang, S.; Knoernschild, K.; Sukotjo, C.; Campbell, S.; Bishal, A.K.; Wu, C.D.; Takoudis, C.G.; Adelino, V.; Yang, B. Improving Polymethyl Methacrylate Resin Using a Novel Titanium Dioxide Coating. J. Prosthodont. 2019, 28, 1011-1017. [CrossRef] [PubMed]

42. Mallick, B.C.; Hsieh, C.-T.; Yin, K.-M.; Gandomi, Y.A.; Huang, K.-T. Review-On Atomic Layer Deposition: Current Progress and Future Challenges. ECS J. Solid State Sci. Technol. 2019, 8, N55-N78. [CrossRef]

43. Bishal, A.K.; Butt, A.; Selvaraj, S.K.; Joshi, B.; Patel, S.B.; Yang, B.; Shukohfar, T.; Sukotjo, C.; Takoudis, C.G. Atomic Layer Deposition in Bio-Nanotechnology: A Brief Overview. Crit. Rev. Biomed. Eng. 2015, 43, 255-276. [CrossRef] [PubMed]

44. He, W. ALD: Atomic Layer Deposition-Precise and Conformal Coating for Better Performance; Springer: London, UK, 2015.

45. Hämäläinen, J.; Ritala, M.; Leskelä, M. Atomic layer deposition of noble metals and their oxides. Chem. Mater. 2014, 26, 786-801. [CrossRef]

46. Ritala, M. Atomic layer deposition. In High-K Gate Dielectrics; Elsevier: Amsterdam, The Netherlands, 2003; pp. 17-64. ISBN 9781420034141.

47. Muñoz-Rojas, D.; Nguyen, V.H.; de la Huerta, C.M.; Aghazadehchors, S.; Jiménez, C.; Bellet, D. Spatial Atomic Layer Deposition (SALD), an emerging tool for energy materials. Application to new-generation photovoltaic devices and transparent conductive materials. Comptes Rendus Phys. 2017, 18, 391-400. [CrossRef]

48. Dey, G.; Elliott, S.D. Copper(I) carbene hydride complexes acting both as reducing agent and precursor for Cu ALD: A study through density functional theory. Theor. Chem. Acc. 2014, 133, 1-7. [CrossRef]

49. Leskelä, M.; Ritala, M. Atomic layer deposition (ALD): From precursors to thin film structures. Thin Solid Films 2002, 409, 138-146. [CrossRef]

50. Huang, S. Improving Polymethyl Methacrylate Resin Using Novel Nano-Ceramic Coating. Master dissertation, University of Illinois at Chicago, Chicago, IL, USA, 2017.

51. Majumder, P.; Katamreddy, R.; Takoudis, C. Effect of film thickness on the breakdown temperature of atomic layer deposited ultrathin $\mathrm{HfO}_{2}$ and $\mathrm{Al}_{2} \mathrm{O}_{3}$ diffusion barriers in copper metallization. J. Cryst. Growth 2007, 309, 12-17. [CrossRef]

52. Xu, R.; Tao, Q.; Yang, Y.; Takoudis, C.G. Atomic layer deposition and characterization of stoichiometric erbium oxide thin dielectrics on Si (100) using (CpMe)3Er precursor and ozone. Appl. Surf. Sci. 2012, 258, 8514-8520. [CrossRef]

53. Leskelä, M.; Ritala, M. ALD precursor chemistry: Evolution and future challenges. Le J. Phys. IV 1999, 9, Pr8-Pr837. [CrossRef]

54. Parker, W.D.; Rondinelli, J.M.; Nakhmanson, S.M. First-principles study of misfit strain-stabilized ferroelectric $\mathrm{SnTiO}_{3}$. Phys. Rev. B 2011, 84, 245126. [CrossRef]

55. Agarwal, R.; Sharma, Y.; Chang, S.; Pitike, K.C.; Sohn, C.; Nakhmanson, S.M.; Takoudis, C.G.; Lee, H.N.; Tonelli, R.; Gardner, J. Room-temperature relaxor ferroelectricity and photovoltaic effects in tin titanate directly deposited on a silicon substrate. Phys. Rev. B 2018, 97, 54109. [CrossRef]

56. Puurunen, R.L. Random Deposition as a Growth Mode in Atomic Layer Deposition. Chem. Vap. Depos. 2004, 10, 159-170. [CrossRef]

57. Fornari, C.I.; Fornari, G.; Paulo, H.d.O.; Abramof, E.; dos Travelho, J.S. Monte Carlo Simulation of Epitaxial Growth. In Epitaxy; Zhong, M., Ed.; BoD-Books on Demand: Norderstedt, Germany, 2018; p. 113.

58. Venables, J. Surface processes in epitaxial growth. In Introduction to Surface and Thin Film Processes; Cambridge University Press: Cambridge, UK, 2000; pp. 144-151. ISBN 0521785006.

59. Itagaki, N.; Nakamura, Y.; Narishige, R.; Takeda, K.; Kamataki, K.; Koga, K.; Hori, M.; Shiratani, M. Growth of single crystalline films on lattice-mismatched substrates through 3D to 2D mode transition. Sci. Rep. 2020, 10, 4669. [CrossRef] [PubMed]

60. Carlsson, J.O.; Martin, P.M. Chemical Vapor Deposition; Third Edit.; Elsevier Ltd.: Amsterdam, The Netherlands, 2010; ISBN 9780815520313.

61. Barna, P.B.; Radnóczi, G. 3-Structure formation during deposition of polycrystalline metallic thin films. In Coffey Optical and Magnetic Applications; Barmak, K., Ed.; Woodhead Publishing: Sawston, UK, 2014; pp. 67-120. ISBN 978-0-85709-057-7. 
62. Vandalon, V.; Kessels, W.M.M. Revisiting the growth mechanism of atomic layer deposition of $\mathrm{Al}_{2} \mathrm{O}_{3}$ : A vibrational sum-frequency generation study. J. Vac. Sci. Technol. A Vacuum, Surfaces, Film. 2017, 35, 05C313. [CrossRef]

63. Cremers, V.; Puurunen, R.L.; Dendooven, J. Conformality in atomic layer deposition: Current status overview of analysis and modelling. Appl. Phys. Rev. 2019, 6, 21302. [CrossRef]

64. Dezelah, C.L. Atomic Layer Deposition BT-Encyclopedia of Nanotechnology. In Encyclopedia of Nanotechnology; Bhushan, B., Ed.; Springer Netherlands: Dordrecht, The Netherlands, 2012; pp. 161-171. ISBN 978-90-481-9751-4.

65. Bishal, A.K.; Sukotjo, C.; Takoudis, C.G. Room temperature $\mathrm{TiO}_{2}$ atomic layer deposition on collagen membrane from a titanium alkylamide precursor. J. Vac. Sci. Technol. A Vacuum Surfaces Film. 2017, 35, 01B134. [CrossRef]

66. Puurunen, R.L. Growth per cycle in atomic layer deposition: A theoretical model. Chem. Vap. Depos. 2003, 9, 249-257. [CrossRef]

67. Kim, J.; Kim, T.W. Initial surface reactions of atomic layer deposition. Jom 2009, 61, 17-22. [CrossRef]

68. Leem, J.; Park, I.; Li, Y.; Zhou, W.; Jin, Z.; Shin, S.; Min, Y.S. Role of $\mathrm{HCl}$ in atomic layer deposition of $\mathrm{TiO}_{2}$ thin films from titanium tetrachloride and water. Bull. Korean Chem. Soc. 2014, 35, 1195-1201. [CrossRef]

69. Matero, R.; Rahtu, A.; Ritala, M. In situ quadrupole mass spectrometry and quartz crystal microbalance studies on the atomic layer deposition of titanium dioxide from titanium tetrachloride and water. Chem. Mater. 2001, 13, 4506-4511. [CrossRef]

70. Ren, J.; Zhang, Y.; Zhang, D.W. Density functional theory study of initial stage of $\mathrm{HfO}_{2}$ atomic layer deposition on hydroxylated $\mathrm{SiO}_{2}$ surface. J. Mol. Struct. Theochem 2007, 803, 23-28. [CrossRef]

71. Lownsbury, J.M.; Gladden, J.A.; Campbell, C.T.; Kim, I.S.; Martinson, A.B.F. Direct Measurements of Half-Cycle Reaction Heats during Atomic Layer Deposition by Calorimetry. Chem. Mater. 2017, 29, 8566-8577. [CrossRef]

72. Richey, N.E.; De Paula, C.; Bent, S.F. Understanding chemical and physical mechanisms in atomic layer deposition. J. Chem. Phys. 2020, 152, 1-17. [CrossRef] [PubMed]

73. Puurunen, R.L. Correlation between the growth-per-cycle and the surface hydroxyl group concentration in the atomic layer deposition of aluminum oxide from trimethylaluminum and water. Appl. Surf. Sci. 2005, 245, 6-10. [CrossRef]

74. Mui, C.; Musgrave, C.B. Atomic layer deposition of $\mathrm{HfO}_{2}$ using alkoxides as precursors. J. Phys. Chem. B 2004, 108, 15150-15164 [CrossRef]

75. Hu, X.; Schuster, J.; Schulz, S.E.; Gessner, T. Surface chemistry of copper metal and copper oxide atomic layer deposition from copper(ii) acetylacetonate: A combined first-principles and reactive molecular dynamics study. Phys. Chem. Chem. Phys. 2015, 17, 26892-26902. [CrossRef] [PubMed]

76. Yang, J.; Cao, K.; Hu, Q.; Wen, Y.; Liu, X.; Chen, R.; Shan, B. Unravelling the selective growth mechanism of AlOx with dimethylaluminum isopropoxide as a precursor in atomic layer deposition: A combined theoretical and experimental study. $J$. Mater. Chem. A 2020, 8, 4308-4317. [CrossRef]

77. $\mathrm{Hu}, \mathrm{Z}$; Turner, C.H. Initial surface reactions of $\mathrm{TiO}_{2}$ atomic layer deposition onto $\mathrm{SiO}_{2}$ surfaces: Density functional theory calculations. J. Phys. Chem. B 2006, 110, 8337-8347. [CrossRef]

78. Elliott, S.D. Predictive process design: A theoretical model of atomic layer deposition. Comput. Mater. Sci. 2005, 33, 20-25. [CrossRef]

79. Shirazi, M.; Elliott, S.D. Multiple proton diffusion and film densification in atomic layer deposition modeled by density functional theory. Chem. Mater. 2013, 25, 878-889. [CrossRef]

80. Cui, C.; Ren, J. A density functional theory study on the reactions of chlorine loss in $\mathrm{ZrO}_{2}$ thin films by atomic-layer deposition. Comput. Theor. Chem. 2012, 979, 38-43. [CrossRef]

81. Athavale, S.D.; Economou, D.J. Molecular dynamics simulation of atomic layer etching of silicon. J. Vac. Sci. Technol. A Vacuum, Surfaces, Film. 1995, 13, 966-971. [CrossRef]

82. Bahramian, A. Study on growth rate of $\mathrm{TiO}_{2}$ nanostructured thin films: Simulation by molecular dynamics approach and modeling by artificial neural network. Surf. Interface Anal. 2013, 45, 1727-1736. [CrossRef]

83. Brown, K.S.; Saggese, C.; Le Monnier, B.P.; Héroguel, F.; Luterbacher, J.S. Simulation of Gas- and Liquid-Phase Layer-By-Layer Deposition of Metal Oxides by Coarse-Grained Modeling. J. Phys. Chem. C 2018, 122, 6713-6720. [CrossRef]

84. He, X.; Luo, L. Theory of the lattice Boltzmann method: From the Boltzmann equation to the lattice Boltzmann equation. Phys. Rev. E 1997, 56, 6811-6817. [CrossRef]

85. Chen, S.; Doolen, G.D. Lattice Boltzmann method for fluid flows. Annu. Rev. Fluid Mech. 1998, 30, 329-364. [CrossRef]

86. Pan, D.; Li, T.; Chien Jen, T.; Yuan, C. Numerical modeling of carrier gas flow in atomic layer deposition vacuum reactor: A comparative study of lattice Boltzmann models. J. Vac. Sci. Technol. A Vacuum, Surfaces, Film. 2014, 32, 01A110. [CrossRef]

87. Ernst, M.; Dietzel, M.; Sommerfeld, M. A lattice Boltzmann method for simulating transport and agglomeration of resolved particles. Acta Mech. 2013, 224, 2425-2449. [CrossRef]

88. Harrison, R.L. Introduction to Monte Carlo simulation. AIP Conf. Proc. 2009, 1204, 17-21. [CrossRef]

89. Mordechai, S. Applications of Monte Carlo Method in Science and Engineering; IntechOpen: London, UK, 2011 ; ISBN 9533076917.

90. Brandimarte, P. Handbook in Monte Carlo simulation: Applications in Financial Engineering, Risk Management, and Economics; John Wiley \& Sons: Hoboken, NJ, USA, 2014; ISBN 1118593642.

91. Kwak, Y.H.; Ingall, L. Exploring Monte Carlo simulation applications for project management. Risk Manag. 2007, 9, 44-57. [CrossRef]

92. Bird, G.A. Monte-Carlo simulation in an engineering context. Prog. Astronaut. Aeronaut. 1981, 74, $239-255$. 
93. Schwille, M.C.; Schössler, T.; Barth, J.; Knaut, M.; Schön, F.; Höchst, A.; Oettel, M.; Bartha, J.W. Experimental and simulation approach for process optimization of atomic layer deposited thin films in high aspect ratio 3D structures. J. Vac. Sci. Technol. A Vac. Surf. Film. 2017, 35, 01B118. [CrossRef]

94. Jin, L.; Li, Y.; Hu, Z.; Chu, J. Full three-dimensional morphology evolution of amorphous thin films for atomic layer deposition. AIP Adv. 2018, 8, 045304. [CrossRef]

95. Deminsky, M.; Knizhnik, A.; Belov, I.; Umanskii, S.; Rykova, E.; Bagatur, A.; Potapkin, B.; Stoker, M.; Korkin, A.; Bagatur'yants, A.; et al. Mechanism and kinetics of thin zirconium and hafnium oxide film growth in an ALD reactor. Surf. Sci. 2004, 549, 67-86. [CrossRef]

96. Adomaitis, R.A. Development of a multiscale model for an atomic layer deposition process. J. Cryst. Growth 2010, 312, 1449-1452. [CrossRef]

97. Weckman, T.; Shirazi, M.; Elliott, S.D.; Laasonen, K. Kinetic Monte Carlo Study of the Atomic Layer Deposition of Zinc Oxide. J Phys. Chem. C 2018, 122, 27044-27058. [CrossRef]

98. Berti, C.; Ulbig, P.; Burdorf, A.; Seippel, J.; Schulz, S. Correlation and prediction of liquid-phase adsorption on zeolites using group contributions based on adsorbate-solid solution theory. Langmuir 1999, 15, 6035-6042. [CrossRef]

99. Khalifa, M.; Lue, L. A group contribution method for predicting the solubility of mercury. Fluid Phase Equilib. 2017, 432, 76-84. [CrossRef]

100. Shahmohammadi, M.; Mukherjee, R.; Takoudis, C.G.; Diwekar, U.M. Optimal design of novel precursor materials for the atomic layer deposition using computer-aided molecular design. Chem. Eng. Sci. 2021, 234, 116416. [CrossRef]

101. Shahmohammadi, M.; Mukherjee, R.; Takoudis, C.G.; Diwekar, U.M. Quantification of Water Impurity in an Atomic Layer Deposition Reactor Using Group Contribution Method. Res. Dev. Mater. Sci. 2021, 15, 1703-1706. [CrossRef]

102. Kim, K.-J.; Diwekar, U.M. Efficient combinatorial optimization under uncertainty. 2. Application to stochastic solvent selection. Ind. Eng. Chem. Res. 2002, 41, 1285-1296. [CrossRef]

103. Cheng, H.-C.; Wang, F.-S. Optimal biocompatible solvent design for a two-stage extractive fermentation process with cell recycling. Comput. Chem. Eng. 2008, 32, 1385-1396. [CrossRef]

104. Gebreslassie, B.H.; Diwekar, U.M. Efficient ant colony optimization for computer aided molecular design: Case study solvent selection problem. Comput. Chem. Eng. 2015, 78, 1-9. [CrossRef]

105. Giovanoglou, A.; Barlatier, J.; Adjiman, C.S.; Pistikopoulos, E.N.; Cordiner, J.L. Optimal solvent design for batch separation based on economic performance. AIChE J. 2003, 49, 3095-3109. [CrossRef]

106. Kim, K.-J.; Diwekar, U.M.; TOMAZI, K.G. Entrainer selection and solvent recycling in complex batch distillation. Chem. Eng. Commun. 2004, 191, 1606-1633. [CrossRef]

107. Marcoulaki, E.C.; Kokossis, A.C. On the development of novel chemicals using a systematic optimisation approach. Part II Solvent design. Chem. Eng. Sci. 2000, 55, 2547-2561. [CrossRef]

108. Samudra, A.P.; Sahinidis, N.V. Optimization-based framework for computer-aided molecular design. AIChE J. 2013, 59, 3686-3701. [CrossRef]

109. Hostrup, M.; Harper, P.M.; Gani, R. Design of environmentally benign processes: Integration of solvent design and separation process synthesis. Comput. Chem. Eng. 1999, 23, 1395-1414. [CrossRef]

110. Mukherjee, R.; Gebreslassie, B.; Diwekar, U.M. Design of novel polymeric adsorbents for metal ion removal from water using computer-aided molecular design. Clean Technol. Environ. Policy 2017, 19, 483-499. [CrossRef]

111. Trevizo, C.; Daniel, D.; Nirmalakhandan, N. Screening alternative degreasing solvents using multivariate analysis. Environ. Sci. Technol. 2000, 34, 2587-2595. [CrossRef]

112. Chemmangattuvalappil, N.G.; Eljack, F.T.; Solvason, C.C.; Eden, M.R. A novel algorithm for molecular synthesis using enhanced property operators. Comput. Chem. Eng. 2009, 33, 636-643. [CrossRef]

113. Sinha, M.; Achenie, L.E.K. Systematic design of blanket wash solvents with recovery considerations. Adv. Environ. Res. 2001, 5 , 239-249. [CrossRef]

114. Eden, M.R.; Jørgensen, S.B.; Gani, R.; El-Halwagi, M.M. A novel framework for simultaneous separation process and product design. Chem. Eng. Process. Process Intensif. 2004, 43, 595-608. [CrossRef]

115. Eljack, F.T.; Eden, M.R. A systematic visual approach to molecular design via property clusters and group contribution methods. Comput. Chem. Eng. 2008, 32, 3002-3010. [CrossRef]

116. Odele, O.; Macchietto, S. Computer aided molecular design: A novel method for optimal solvent selection. Fluid Phase Equilib. 1993, 82, 47-54. [CrossRef]

117. Pistikopoulos, E.N.; Stefanis, S.K. Optimal solvent design for environmental impact minimization. Comput. Chem. Eng. 1998, 22, 717-733. [CrossRef]

118. Salazar, J.; Diwekar, U.M.; Joback, K.; Berger, A.H.; Bhown, A.S. Solvent selection for post-combustion $\mathrm{CO}_{2}$ capture. Energy Procedia 2013, 37, 257-264. [CrossRef]

119. Churi, N.; Achenie, L.E.K. Novel mathematical programming model for computer aided molecular design. Ind. Eng. Chem. Res. 1996, 35, 3788-3794. [CrossRef]

120. Duvedi, A.P.; Achenie, L.E.K. Designing environmentally safe refrigerants using mathematical programming. Chem. Eng. Sci. 1996, 51, 3727-3739. [CrossRef] 
121. Xu, W.; Diwekar, U.M. Environmentally friendly heterogeneous azeotropic distillation system design: Integration of EBS selection and IPS recycling. Ind. Eng. Chem. Res. 2005, 44, 4061-4067. [CrossRef]

122. $\mathrm{Xu}, \mathrm{W}$; Diwekar, U.M. Multi-objective integrated solvent selection and solvent recycling under uncertainty using a new genetic algorithm. Int. J. Environ. Pollut. 2007, 29, 70-89. [CrossRef]

123. Folic, M.; Adjiman, C.S.; Pistikopoulos, E.N. Computer-aided solvent design for reactions: Maximizing product formation. Ind. Eng. Chem. Res. 2008, 47, 5190-5202. [CrossRef]

124. Lin, B.; Chavali, S.; Camarda, K.; Miller, D.C. Computer-aided molecular design using Tabu search. Comput. Chem. Eng. 2005, 29, 337-347. [CrossRef]

125. Camarda, K.V.; Sunderesan, P. An Optimization Approach to the Design of Value-Added Soybean Oil Products. Ind. Eng. Chem. Res. 2005, 44, 4361-4367. [CrossRef]

126. Karunanithi, A.T.; Achenie, L.E.K.; Gani, R. A computer-aided molecular design framework for crystallization solvent design Chem. Eng. Sci. 2006, 61, 1247-1260. [CrossRef]

127. Yamamoto, H.; Tochigi, K. Computer-aided molecular design to select foaming agents using a neural network method. Ind. Eng. Chem. Res. 2008, 47, 5152-5156. [CrossRef]

128. Benavides, P.T.; Gebreslassie, B.H.; Diwekar, U.M. Optimal design of adsorbents for NORM removal from produced water in natural gas fracking. Part 2: CAMD for adsorption of radium and barium. Chem. Eng. Sci. 2015, 137, 977-985. [CrossRef]

129. Doshi, R.K.; Mukherjee, R.; Diwekar, U.M. Application of Adsorbate Solid Solution Theory To Design Novel Adsorbents for Arsenic Removal Using CAMD. ACS Sustain. Chem. Eng. 2018, 6, 2603-2611. [CrossRef]

130. Qi, F.X.Y.; Liu, K.; Ma, D.K.; Cai, F.F.; Liu, M.; Xu, Q.L.; Chen, W.; Qi, C.Z.; Yang, D.P.; Huang, S.M. Dual active sites fabricated through atomic layer deposition of $\mathrm{TiO}_{2}$ on $\mathrm{MoS}_{2}$ nanosheet arrays for highly efficient electroreduction of $\mathrm{CO} 2$ to ethanol. J. Mater. Chem. A 2021, 9, 6790-6796. [CrossRef]

131. Cho, Y.; Kim, S.H.; Kim, B.S.; Kim, Y.; Jeon, W. Modulation of the adsorption chemistry of a precursor in atomic layer deposition to enhance the growth per cycle of a $\mathrm{TiO}_{2}$ thin film. Phys. Chem. Chem. Phys. 2021, 23, 2568-2574. [CrossRef]

132. Park, B.E.; Oh, I.K.; Lee, C.W.; Lee, G.; Shin, Y.H.; Lansalot-Matras, C.; Noh, W.; Kim, H.; Lee, H.B.R. Effects of Cl-Based Ligand Structures on Atomic Layer Deposited $\mathrm{HfO}_{2}$. J. Phys. Chem. C 2016, 120, 5958-5967. [CrossRef]

133. Sasinska, A.; Bialuschewski, D.; Islam, M.M.; Singh, T.; Deo, M.; Mathur, S. Experimental and Theoretical Insights into Influence

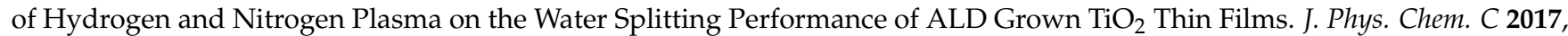
121, 15538-15548. [CrossRef]

134. Iatsunskyi, I.; Vasylenko, A.; Viter, R.; Kempinski, M.; Nowaczyk, G.; Jurga, S.; Bechelany, M. Tailoring of the electronic properties of ZnO-polyacrylonitrile nanofibers: Experiment and theory. Appl. Surf. Sci. 2017, 411, 494-501. [CrossRef]

135. Sarkar, S.; Patel, R.L.; Liang, X.H.; Park, J. Unveiling the Role of $\mathrm{CeO}_{2}$ Atomic Layer Deposition Coatings on $\mathrm{LiMn}_{2} \mathrm{O}_{4} \mathrm{Cathode}$ Materials: An Experimental and Theoretical Study. ACS Appl. Mater. Interfaces 2017, 9, 30599-30607. [CrossRef] [PubMed]

136. Kim, D.K.; Chae, J.; Hong, S.B.; Park, H.; Jeong, K.S.; Park, H.W.; Kwon, S.R.; Chung, K.B.; Cho, M.H. Interface engineering for a stable chemical structure of oxidized-black phosphorus via self-reduction in AlOx atomic layer deposition. Nanoscale 2018, 10, 22896-22907. [CrossRef] [PubMed]

137. Lawniczak-Jablonska, K.; Wolska, A.; Kuzmiuk, P.; Rejmak, P.; Kosiel, K. Local atomic order of the amorphous TaO $\mathrm{x}_{\mathrm{x}}$ thin films in relation to their chemical resistivity. RSC Adv. 2019, 9, 35727-35734. [CrossRef]

138. Lee, S.; Baek, G.; Lee, J.H.; Van, T.T.N.; Ansari, A.; Shong, B.; Park, J.S. Molecular layer deposition of indicone and organicinorganic hybrid thin films as flexible transparent conductor. Appl. Surf. Sci. 2020, 525, 146383. [CrossRef]

139. Song, Z.X.; Zhu, Y.N.; Liu, H.S.; Banis, M.N.; Zhang, L.; Li, J.J.; Doyle-Davis, K.; Li, R.Y.; Sham, T.K.; Yang, L.J.; et al. Engineering the Low Coordinated Pt Single Atom to Achieve the Superior Electrocatalytic Performance toward Oxygen Reduction. SMALL 2020, 16, 2003096. [CrossRef]

140. Choi, S.; Ansari, A.; Yun, H.J.; Kim, H.; Shong, B.; Choi, B.J. Growth of Al-rich AlGaN thin films by purely thermal atomic layer deposition. J. Alloys Compd. 2021, 854, 157186. [CrossRef]

141. He, Y.F.; Pham, H.; Gao, Y.; Patel, R.L.; Sarkar, S.; Liang, X.H.; Park, J. Discovery of an Unexpected Metal Dissolution of Thin-Coated Cathode Particles and Its Theoretical Explanation. Adv. Theory Simulations 2020, 3, 2000002. [CrossRef]

142. Zou, F.; Liu, Y.; Mou, C.; Zhu, S. Optimization of Refractive Index Sensitivity in Nanofilm-Coated Long-Period Fiber Gratings near the Dispersion Turning Point. J. Light. Technol. 2020, 38, 889-897. [CrossRef]

143. Bermudez, V.M. Theoretical study of the adsorption of Lewis acids on $\mathrm{MoS}_{2}$ in relation to atomic layer deposition of $\mathrm{Al}_{2} \mathrm{O}_{3} . J . \mathrm{Vac}_{\text {. }}$ Sci. Technol. A 2020, 38, 062412. [CrossRef]

144. Petersen, M. Theoretical study of reaction mechanisms of $\mathrm{ZrCl}_{4}$ with hydrated and hydroxlated Si(100) surfaces. Comput. Mater. Sci. 2004, 30, 77-80. [CrossRef]

145. Jung, J.-S.S.; Lee, S.-K.K.; Hong, C.-S.S.; Shin, J.-H.H.; Kim, J.-M.M.; Kang, J.-G.G. Atomic layer deposition of $\mathrm{ZrO}_{2}$ thin film on Si (100) using \{ $\eta$ 5: $\eta 1-\mathrm{Cp}(\mathrm{CH} 2) 3 \mathrm{NMe}\} \mathrm{Zr}$ (NMe2) 2/O3 as precursors. Thin Solid Films 2015, 589, 831-837. [CrossRef]

146. Gharachorlou, A.; Detwiler, M.D.; Gu, X.K.; Mayr, L.; Klötzer, B.; Greeley, J.; Reifenberger, R.G.; Delgass, W.N.; Ribeiro, F.H.; Zemlyanov, D.Y. Trimethylaluminum and Oxygen Atomic Layer Deposition on Hydroxyl-Free Cu(111). ACS Appl. Mater. Interfaces 2015, 7, 16428-16439. [CrossRef]

147. Seo, S.; Yeo, B.C.; Han, S.S.; Yoon, C.M.; Yang, J.Y.; Yoon, J.; Yoo, C.; Kim, H.J.; Lee, Y.B.; Lee, S.J.; et al. Reaction Mechanism of Area-Selective Atomic Layer Deposition for $\mathrm{Al}_{2} \mathrm{O}_{3}$ Nanopatterns. ACS Appl. Mater. Interfaces 2017, 9, 41607-41617. [CrossRef] 
148. Karasulu, B.; Vervuurt, R.H.J.; Kessels, W.M.M.; Bol, A.A. Continuous and ultrathin platinum films on graphene using atomic layer deposition: A combined computational and experimental study. Nanoscale 2016, 8, 19829-19845. [CrossRef]

149. Pan, D.; Ma, L.; Xie, Y.; Jen, T.C.; Yuan, C. On the physical and chemical details of alumina atomic layer deposition: A combined experimental and numerical approach. J. Vac. Sci. Technol. A Vacuum, Surfaces, Film. 2015, 33, 021511. [CrossRef]

150. Halder, A.; Lenardi, C.; Timoshenko, J.; Mravak, A.; Yang, B.; Kolipaka, L.K.; Piazzoni, C.; Seifert, S.; Bonacic-Koutecky, V.; Frenkel, A.I.; et al. $\mathrm{CO}_{2}$ Methanation on Cu-Cluster Decorated Zirconia Supports with Different Morphology: A Combined Experimental In Situ GIXANES/GISAXS, Ex Situ XPS and Theoretical DFT Study. ACS Catal. 2021, 11, 6210-6224. [CrossRef]

151. Perevalov, T.V.; Prosvirin, I.P.; Suprun, E.A.; Mehmood, F.; Mikolajick, T.; Schroeder, U.; Gritsenko, V.A. The atomic and electronic structure of $\mathrm{Hf}_{0.5} \mathrm{Zr}_{0.5} \mathrm{O}_{2}$ and $\mathrm{Hf}_{0.5} \mathrm{Zr}_{0.5} \mathrm{O}_{2}$ :La films. J. Sci. Mater. DEVICES 2021, 6, 595-600. [CrossRef]

152. Yu, N.K.; Moon, C.H.; Park, J.; Lee, H.B.R.; Shong, B. Evaluation of silicon tetrahalide precursors for low-temperature thermal atomic layer deposition of silicon nitride. Appl. Surf. Sci. 2021, 565, 150603. [CrossRef]

153. Beer, S.M.J.; Boysen, N.; Muriqi, A.; Zanders, D.; Berning, T.; Rogalla, D.; Bock, C.; Nolan, M.; Devi, A. A study on the influence of ligand variation on formamidinate complexes of yttrium: New precursors for atomic layer deposition of yttrium oxide. Dalt. Trans. 2021, 50, 12944-12956. [CrossRef] [PubMed]

154. Borbon-Nunez, H.A.; Muniz, J.; El Hachimi, A.G.; Frausto-Silva, D.; Gutierrez-Diaz, J.L.; Dominguez, D.; Tiznado, H.; CuentasGallegos, A.K. Effect of oxygen based functional groups on the nucleation of $\mathrm{TiO}_{2}$ by atomic layer deposition: A theoretical and experimental study. Mater. Chem. Phys. 2021, 267, 124588. [CrossRef]

155. Boukhari, A.; Deghfel, B.; Mahroug, A.; Amari, R.; Selmi, N.; Kheawhom, S.; Mohamad, A.A. Thickness effect on the properties of Mn-doped $\mathrm{ZnO}$ thin films synthesis by sol-gel and comparison to first-principles calculations. Ceram. Int. 2021, 47, 17276-17285. [CrossRef]

156. Zhu, X.P.; Guo, J.J.; Li, X.X.; Zhou, R.D.; Wang, D.; Zhao, W. Evolvement Investigation of Secondary Electron Emission for Ultrathin MgO Coatings Prepared by Atomic Layer Deposition. Appl. Sci. 2021, 11, 4801. [CrossRef]

157. Weckman, T.; Laasonen, K. First principles study of the atomic layer deposition of alumina by TMA-H ${ }_{2} \mathrm{O}-$ process. Phys. Chem. Chem. Phys. 2015, 17, 17322-17334. [CrossRef]

158. Travis, C.D.; Adomaitis, R.A. Modeling alumina atomic layer deposition reaction kinetics during the trimethylaluminum exposure. Theor. Chem. Acc. 2014, 133, 3-11. [CrossRef]

159. Xu, K.; Ye, P.D. Theoretical study of atomic layer deposition reaction mechanism and kinetics for aluminum oxide formation at graphene nanoribbon open edges. J. Phys. Chem. C 2010, 114, 10505-10511. [CrossRef]

160. Kayanuma, M.; Choe, Y.-K.; Hagiwara, T.; Kameda, N.; Shimoi, Y. Theoretical Study of the Mechanism for the Reaction of Trimethylaluminum with Ozone. ACS Omega 2021, 6, 26282-26292. [CrossRef]

161. Puurunen, R.L. Growth per cycle in atomic layer deposition: Real application examples of a theoretical model. Chem. Vap. Depos. 2003, 9, 327-332. [CrossRef]

162. Burgess, D.R.; Maslar, J.E.; Hurst, W.S.; Moore, E.F.; Kimes, W.A.; Fink, R.R.; Nguyen, N. V Atomic Layer Deposition-Process Models and Metrologies. AIP Conf. Proc. 2005, 788, 141-146. [CrossRef]

163. Seo, S.; Nam, T.; Lee, H.B.R.; Kim, H.; Shong, B. Molecular oxidation of surface $-\mathrm{CH}_{3}$ during atomic layer deposition of $\mathrm{Al}_{2} \mathrm{O}_{3}$ with $\mathrm{H}_{2} \mathrm{O}, \mathrm{H}_{2} \mathrm{O}_{2}$, and $\mathrm{O}_{3}$ : A theoretical study. Appl. Surf. Sci. 2018, 457, 376-380. [CrossRef]

164. Widjaja, Y.; Musgrave, C.B. Quantum chemical study of the mechanism of aluminum oxide atomic layer deposition. Appl. Phys. Lett. 2002, 80, 3304-3306. [CrossRef]

165. Elliott, S.D. Models for ALD and MOCVD growth of rare earth oxides. Top. Appl. Phys. 2006, 106, 73-86. [CrossRef]

166. Park, S.; Park, B.E.; Yoon, H.; Lee, S.; Nam, T.; Cheon, T.; Kim, S.H.; Cheon, H.; Im, S.; Seong, T.; et al. Comparative study on atomic layer deposition of $\mathrm{HfO}_{2}$ : Via substitution of ligand structure with cyclopentadiene. J. Mater. Chem. C 2020, 8, 1344-1352. [CrossRef]

167. Mukhopadhyay, A.B.; Musgrave, C.B.; Sanz, J.F. Atomic layer deposition of hafnium oxide from hafnium chloride and water. J Am. Chem. Soc. 2008, 130, 11996-12006. [CrossRef] [PubMed]

168. Mastail, C.; Lanthony, C.; Olivier, S.; Ducéré, J.-M.; Landa, G.; Estève, A.; Rouhani, M.D.; Richard, N.; Dkhissi, A. Introducing densification mechanisms into the modelling of $\mathrm{HfO}_{2}$ atomic layer deposition. Thin Solid Films 2012, 520, 4559-4563. [CrossRef]

169. $\mathrm{Hu}, \mathrm{Z}$; Turner, C.H. Atomic layer deposition of $\mathrm{TiO}_{2}$ from $\mathrm{TiI}_{4}$ and $\mathrm{H}_{2} \mathrm{O}$ onto $\mathrm{SiO}_{2}$ surfaces: Ab initio calculations of the initial reaction mechanisms. J. Am. Chem. Soc. 2007, 129, 3863-3878. [CrossRef]

170. Zhou, G.; Ren, J.; Zhang, S. Initial growth mechanisms of $\mathrm{ZrO}_{2}$ and $\mathrm{TiO}_{2}$ thin films using cycloheptatrienyl-cyclopentadienyl heteroleptic precursors: A comparative study by density functional theory. Appl. Surf. Sci. 2013, 283, 968-974. [CrossRef]

171. Han, J.H.; Gao, G.; Widjaja, Y.; Garfunkel, E.; Musgrave, C.B. A quantum chemical study of $\mathrm{ZrO}_{2}$ atomic layer deposition growth reactions on the $\mathrm{SiO} 2$ surface. Surf. Sci. 2004, 550, 199-212. [CrossRef]

172. Ren, J.; Cui, C.; Zhou, G.; Liu, Y.; Hu, Y.; Wang, B. A theoretical study on initial growth mechanism of $\mathrm{ZrO}_{2}$ film using cyclopentadienyl-type precursor. Thin Solid Films 2011, 519, 3716-3721. [CrossRef]

173. Zhou, G.; Ren, J.; Zhang, S. Theoretical study on the initial reaction mechanisms of ansa-metallocene zirconium precursor on hydroxylated Si(100) surface. J. Mol. Model. 2016, 22, 117. [CrossRef]

174. Elliott, S.D.; Dey, G.; Maimaiti, Y. Classification of processes for the atomic layer deposition of metals based on mechanistic information from density functional theory calculations. J. Chem. Phys. 2017, 146, 052822. [CrossRef] [PubMed] 
175. Doan, H.A.; Li, Z.; Farha, O.K.; Hupp, J.T.; Snurr, R.Q. Theoretical insights into direct methane to methanol conversion over supported dicopper oxo nanoclusters. Catal. Today 2018, 312, 2-9. [CrossRef]

176. Dey, G.; Elliott, S.D. Mechanism for the atomic layer deposition of copper using diethylzinc as the reducing agent: A density functional theory study using gas-phase molecules as a model. J. Phys. Chem. A 2012, 116, 8893-8901. [CrossRef] [PubMed]

177. Phung, Q.M.; Pourtois, G.; Swerts, J.; Pierloot, K.; Delabie, A. Atomic layer deposition of ruthenium on ruthenium surfaces: A theoretical study. J. Phys. Chem. C 2015, 119, 6592-6603. [CrossRef]

178. Filatova, E.A.; Hausmann, D.; Elliott, S.D. Investigating routes toward atomic layer deposition of silicon carbide: Ab initio screening of potential silicon and carbon precursors. J. Vac. Sci. Technol. A Vacuum, Surfaces, Film. 2017, 35, 01B103. [CrossRef]

179. Cremers, V.; Geenen, F.; Detavernier, C.; Dendooven, J. Monte Carlo simulations of atomic layer deposition on 3D large surface area structures: Required precursor exposure for pillar- versus hole-type structures. J. Vac. Sci. Technol. A Vacuum, Surfaces, Film. 2017, 35, 01B115. [CrossRef]

180. Murray, C.; Elliott, S.D. Density functional theory predictions of the composition of atomic layer deposition-grown ternary oxides. ACS Appl. Mater. Interfaces 2013, 5, 3704-3715. [CrossRef]

181. Hu, Z.; Shi, J.; Heath Turner, C. Molecular dynamics simulation of the $\mathrm{Al}_{2} \mathrm{O}_{3}$ film structure during atomic layer deposition. Mol. Simul. 2009, 35, 270-279. [CrossRef] 